\title{
Zebrus pallaoroi sp. nov.: a new species of goby (Actinopterygii: Gobiidae) from the Mediterranean Sea with a DNA-based phylogenetic analysis of the Gobius-lineage
}

\author{
Marcelo Kovačić \\ Natural History Museum Rijeka, Lorenzov prolaz 1, HR-510oo Rijeka, Croatia \\ marcelo@prirodoslovni.com
}

Radek Šanda

Department of Zoology, National Museum, Václavské nám. 68, 110 oo Prague, Czech Republic

Katarína Čekovská

Department of Ecology, Faculty of Science, Charles University, Viničná 7, 12844 Prague, Czech Republic

\section{Tereza Soukupová}

Department of Ecology, Faculty of Science, Charles University, Viničná 7, 12844 Prague, Czech Republic

\section{Jasna Vukić}

Department of Ecology, Faculty of Science, Charles University, Viničná 7, 12844 Prague, Czech Republic

\footnotetext{
Abstract

The gobies (Gobiidae) are the most diverse fish family in the Mediterranean Sea. Nevertheless, knowledge on their diversity, taxonomy, and phylogenetic relationships is still inadequate. The phylogenetic analyses reveal two genetically highly distinct clades among specimens identified as Zebrus zebrus. A new species, Zebrus pallaoroi sp. nov., is described based on an integrative approach. The neotype of Zebrus zebrus is designated. Genetic data confirm a pronounced level of divergence between Z. pallaoroi and Z. zebrus, with the mean genetic distance on cytochrome b being $18.1 \%$ and $1.07 \%$ on rhodopsin. Phylogenetic relationships within the Gobius-lineage were estimated on both markers. Morphologically, Z. pallaoroi is distinguished from the only congener $Z$. zebrus by having a snout longer than its eye, posterior nostril about $4 / 5^{-9} / 10$ of the anterior nostril, eye diameter $4.3^{-4.7}$ in head length, ventrolateral head ridges transversally connected on the anterior side by a short transversal ridge, anterior membrane midline 
depth about $2 / 3$ of the spinous ray, head canal pore $\alpha$ diameter about half of the distance between pore $\rho$ and $\rho^{1}$, suborbital sensory papillae row $5^{i}$ going downwards to or near the level of row $d$, the distance between row $5 i$ and row $d$ absent or much smaller than the length of row $5 i$, and the body with ten to eleven vertical dark brown bands. Zebrus pallaoroi was recorded from the southern Adriatic, northern Ionian, and northern and western Aegean Seas, and is a cryptobenthic fish from very shallow waters.

\section{Keywords}

cryptic species - cryptobenthic fishes - genetic diversity - Gobiinae - phylogeny - Zebrus pallaoroi sp. nov

Zoobank: http://zoobank.org/urn:lsid:zoobank.org:pub:3E49FAFC-8EDE-4627-9F26-B9F2C7F12A6B and http://zoobank.org/urn:lsid:zoobank.org:act:01212C4A-3C6A-48D1-8FoF-24E133039E6o

\section{Introduction}

The gobies (Gobiidae) are the most species-rich fish family (Fricke et al., 2020a), and one of the most evolutionary successful fish groups. It is also the most diverse fish family of the European seas (Miller, 1986). European gobies belong to three distinct evolutionary lineages; the Gobius-, Pomatoschistus-, and Aphia-lineages (Agorreta et al., 2013). However, knowledge on the diversity and taxonomy of European gobies is still inadequate, and the distribution of many species is not well known. New species are still being described from European seas, not only from bathyal depths (Kovačić et al., 2018, $2019 b$ ) and deeper shelves (Kovačić et al., 2016, 2017; Engin \& Seyhan, 2017; Schliewen et al., 2019), but also from shallow coastal areas with depths of only a few meters (Kovačić \& Šanda, 2016; Engin \& Innal, 2017; Engin et al., 2018a). Six of these newly discovered species belong to the Pomatoschistus-lineage (Kovačić et al., 2016, 2017, 2018; Engin \& Seyhan, 2017; Engin \& Innal, 2017; Schliewen et al., 2019), while only two belong to the Gobius-lineage (Kovačić \& Šanda, 2016; Kovačić et al., 2019b). One more gobiid species described from the
Mediterranean Sea is, in fact, a Lessepsian migrant, curiously only discovered out of its native range (Engin et al., 2018a).

Cryptic diversity can be successfully revealed by genetic methods (Hebert et al., 2003), and the species-rich family Gobiidae has already shown a marked degree of cryptic diversity in studied examples (Victor, 2014). However, among European and Mediterranean marine gobiid species, there has been just one published example (Kovačić \& Šanda, 2016) of a cryptic species hidden among morphologically similar, valid, and well-known species. The morphologically cryptic species, Gobius incognitus Kovačić \& Šanda, 2016, was first detected among specimens originally identified as the well-known and common infralittoral Gobius bucchichi Steindachner, 1870, by detailed genetic investigations, and it turned out to be also well-diagnosable morphologically. Furthermore, Gobius incognitus was found to be widespread in the Mediterranean Sea, while the confirmed distribution of G. bucchichi is restricted only to the Adriatic and Ionian Seas (Kovačić \& Šanda, 2016). The sand goby Pomatoschistus minutus (Pallas, 1770) is another European gobiid species known to show large genetic differences 
between populations, and which is expected to include cryptic species (Stefanni \& Thorley, 2003; Stefanni et al., 2003; Gysels et al., 2004; Boissin et al., 2011). However, no morphological or taxonomical efforts have addressed this problem.

The genus Zebrus de Buen, 1930 was erected as a subgenus of Gobius to host small cryptobenthic Mediterranean gobies Gobius zebrus Risso, 1827 and Gobius thori de Buen, 1928 , though the latter is now synonym of Thorogobius ephippiatus (Lowe, 1839) (de Buen, 1930; Miller, 1973). The subgenus Zebrus was first elevated to the rank of genus by Miller (1966), but without any data or explanation supporting this decision. Later, Miller (1977) provided the redescription of Zebrus as a monotypic genus and the redescription of the only species within it, Z. zebrus.

The phylogenetic analyses reported here reveal two genetically distinct clades among samples first identified as Z. zebrus by the valid diagnostic characters of this species (Miller, 1977; Miller, 1986). The aim of the present paper is to describe a new overlooked species based on its morphological and genetic differences from $Z$. zebrus, as well as to designate the neotype of $Z$. zebrus.

\section{Materials and methods}

\section{Morphological methods}

Morphometric methods, measurements, and definitions follow those used in Schliewen \& Kovačić (2008). Measurements smaller than $20 \mathrm{~mm}$ were taken with interactively selected points in Olympus cellSens Entry 2.2 software using an Olympus SC18o camera and Olympus U-TVO.5XC-3 camera adapter on an Olympus SZX1o stereomicroscope. Specimens were repositioned for each measuriment in such a way that the plane in which the line segment lies is perpendicular to the objective to avoid parallax distortion of length. Measurements $>20 \mathrm{~mm}$ were taken by digital caliper (i.e., direct point to point measurements). Specimen length is presented as the standard length + caudal-fin length. Standard length (SL) is measured from the median anterior point of the upper lip to the base of the caudal fin (posterior end of the hypural plate). Morphometric data are given as a ratio in the text and as percentages of SL in the tables. Count of scales and fins follows Schliewen et al. (2018). Terminology of the lateral-line system follows Sanzo (1911) and Miller (1986). The term "ventrolateral head ridge" (Kovačić et al., 2019a) describes the ridge on the underside of the head formed by the ventral margin of the cheek and matches the "hypohyal ridge" of Miller \& El-Tawil (1974). The type material and the comparative material were reversibly stained in a $2 \%$ solution of Cyanine Blue in distilled water (Saruwatari et al., 1997) for the positive data on morphometrics, fin counts, scales, head canals, and sensory papillae rows. The specimens were briefly air-dried and then incubated in the staining solution for 6o seconds. After examination, they were returned to the original preservative $(70 \%$ ethanol) where they returned to the original state (i.e., completely lost any trace of the prior staining). The original preservative, having diluted stain from the specimens, was replaced with fresh ethanol after 24 hours. Digital X-ray radiographs of the Zebrus pallaoroi sp. nov type material and the comparative material of Z. zebrus and Millerigobius macrocephalus (Kolombatović, 1891) were taken from the left side using UltraFocus Digital Radiography System (Faxitron Bioptics, Arizona, USA), housed in the Zoological State Collection, Munich, Germany. The dorsal pterygiophore insertion pattern follows the terminology of Birdsong et al. (1988).

The type material and the comparative material used for morphology have been deposited 
in the National Museum, Prague (NMP), Czech Republic. Additional non-type material of the new species revealed by molecular methods that was used for molecular analyses and for geographic and ecological results was available as tissue only (NMP collection), and is listed in table S1.

\section{Molecular methods}

The right pectoral fin was clipped and preserved in 96\% ethanol for molecular analyses, while voucher specimens were labelled, preserved in $4 \%$ formaldehyde, and later transferred to $70 \%$ ethanol for permanent storage. Vouchers are deposited in the NMP. A list of the Zebrus and Millerigobius specimens included in the genetic analyses with all details is provided in table S1. Apart from Zebrus and Millerigobius, additional species were included in the molecular analyses to complement the phylogenetic datasets by including representatives of the European gobiid genera from the Gobius-lineage sensu Agorreta et al. (2013) to maximum extent (table 1). DNA was extracted using a Geneaid ${ }^{\circledR}$ DNA Isolation Kit. Samples were amplified for the mitochondrial gene cytochrome $b$ using either primers AJG and $\mathrm{H}_{5}$ (Akihito et al., 200o) or GluF and ThrR (Machordom \& Doadrio, 2001), and for the nuclear gene rhodopsin with primers RhodF and RhodR (Taylor \& Hellberg, 2005). The polymerase chain reaction (PCR) was performed in $25 \mu \mathrm{l}$ volume containing $12.5 \mu \mathrm{l}$ of PPP Master Mix (TopBio), 9.7 $\mu$ l of ultrapure $\mathrm{H}_{2} \mathrm{O}$, $0.65 \mu \mathrm{l}$ of each primer, and $2 \mu \mathrm{l}$ of DNA isolate. Amplification of cytochrome b was carried out according to the protocol described in Šanda et al. (2008). For rhodopsin, the PCR cycle consisted of an initial denaturation at $94^{\circ} \mathrm{C}$ for 5 min, followed by 35 cycles of denaturation, annealing, and elongation $\left(94^{\circ} \mathrm{C}\right.$ for $45 \mathrm{~s}, 53^{\circ} \mathrm{C}$ for $1 \mathrm{~min}$, and $72^{\circ} \mathrm{C}$ for $2 \mathrm{~min}$ ), and the final elongation at $72^{\circ} \mathrm{C}$ for $10 \mathrm{~min}$. PCR products were purified with ExoSAP-IT and sequencing was performed by Macrogen Europe (Netherlands). For cytochrome b sequencing in Zebrus and Millerigobius, specific internal primers were designed: ZzebFi (5'- GYG CCA CMG TYA TTA CTA ACC-3') and ZzebR1 (5'- GAA KGG KAC TTT GTC GGA GT CG-3'), while the amplification primers were used for sequencing of other species. Rhodopsin was sequenced with newly designed internal primers RHSQF1 (5'- GCC TCC ACC TGG KTC ATG GC-3') and RHSQRı (5'- CAG GAA GCC GAT CAC CAT GA-3').

Sequences were visually checked in Chromas v2.6.4 and aligned in Bioedit v7.2.6.1 (Hall, 1999). The rhodopsin dataset contained heterozygotic positions, and sequences of Zebrus and Millerigobius were phased to alleles using the program PHASE v2.1.1 (Stephens et al., 2001) with a probability threshold of o.9. Sequences of each species were phased separately. Phased data were used in all analyses. Sequences of other species were not phased. To investigate the phylogenetic relationship of the target species, comparative sequences were downloaded from GenBank (table 1). Sequences of representatives from the Pomatoschistus lineage sensu Agorreta et al. (2013) were used as the outgroup for both markers (table 1). New sequences were deposited in GenBank with the accession numbers MW196294-MW19636o for cytochrome b and MW1955O1-MW195529 for rhodopsin (table 1, supplementary table S1).

Before analysing sequence data, the best fitting model of nucleotide substitution for each subset of positions inside codons was assessed using PartitionFinder 2 (Lanfear et al., 2017) based on Bayesian information criterion (BIC), and under the option all models. The selected models for the three partitions for cytochrome b were $\mathrm{TRN}+\mathrm{G}, \mathrm{K} 8 \mathrm{O}+\mathrm{I}+\mathrm{G}$ 


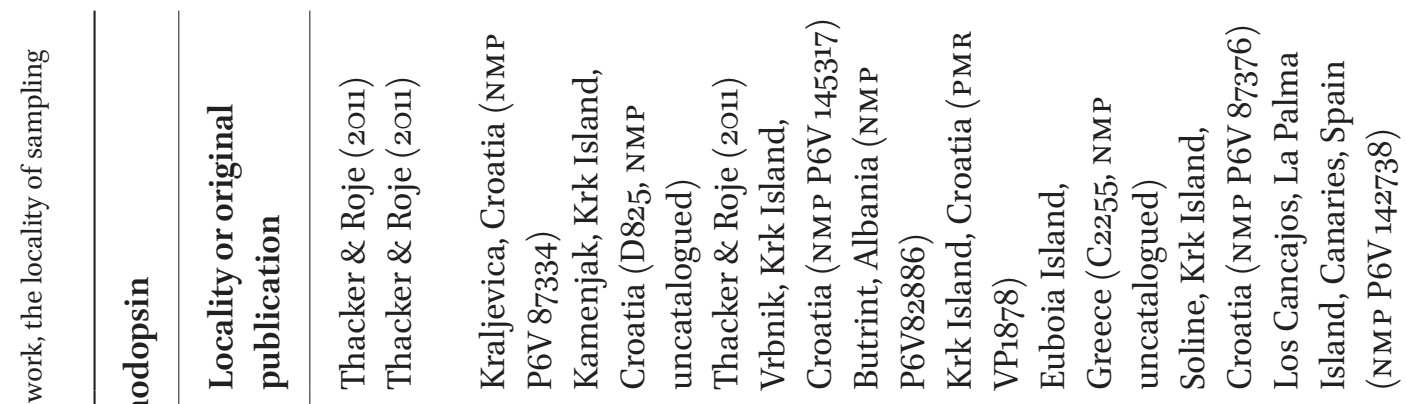

๖ำ

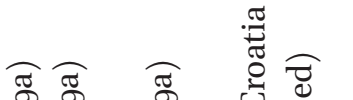

คั

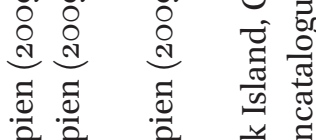

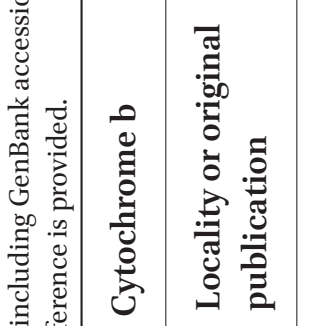

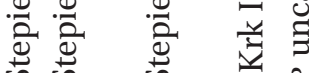

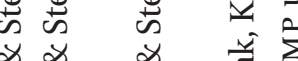

\& \& के त्ञ

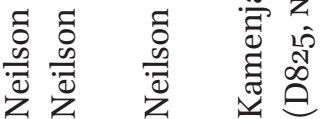

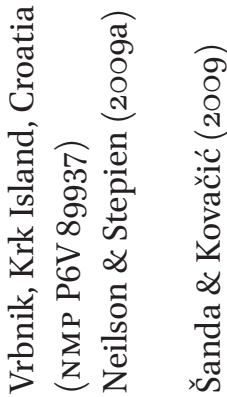

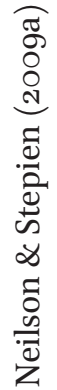

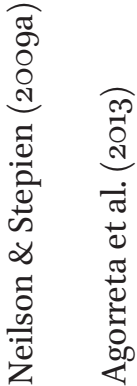

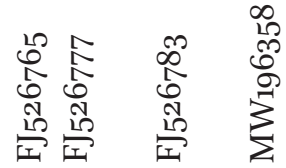

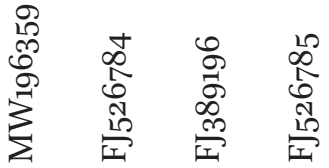

$\begin{array}{ll}1 & \infty \\ \infty & 0 \\ 0 & 0 \\ 0 & 1 \\ \text { Nิ } & 7 \\ 1 & 1\end{array}$

点

㢤.

ज्ञ

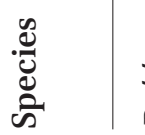

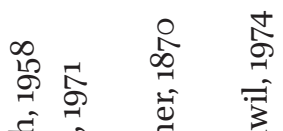

氙

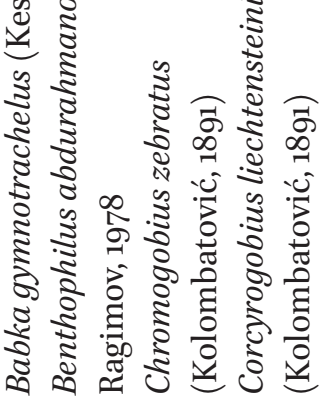

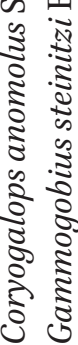

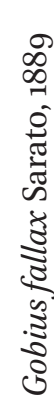

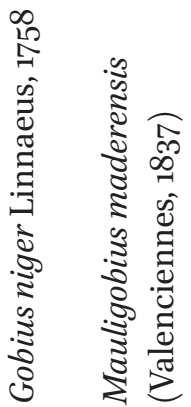




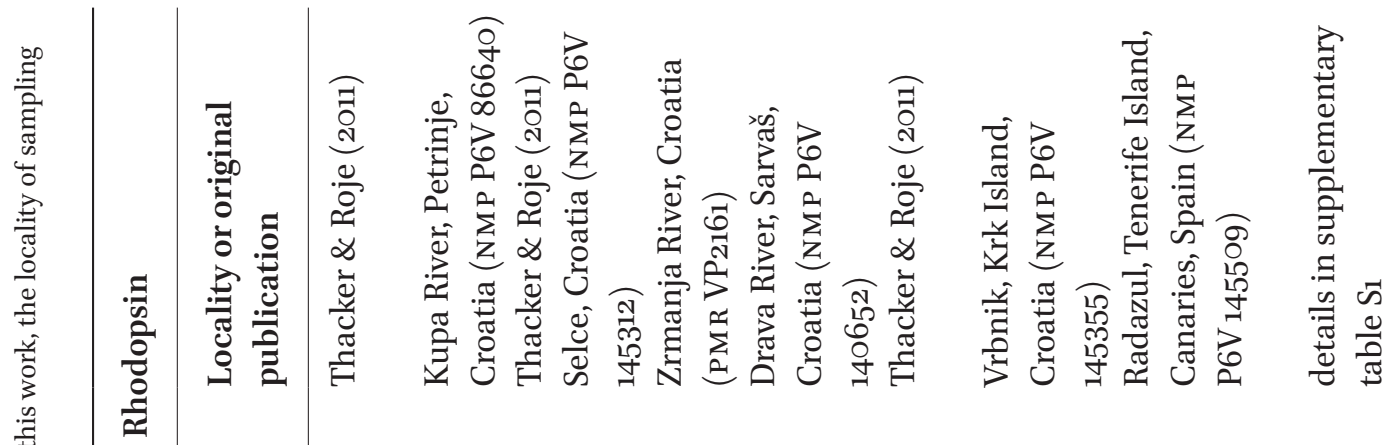

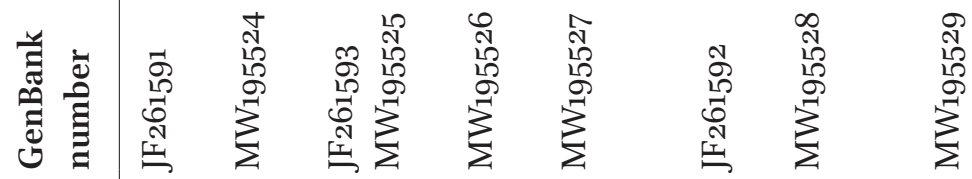

宁

‡

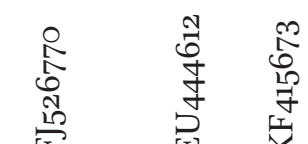

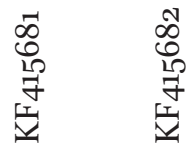

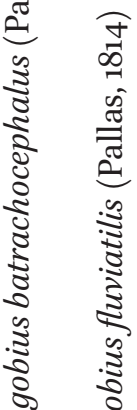

ज्ञ

II

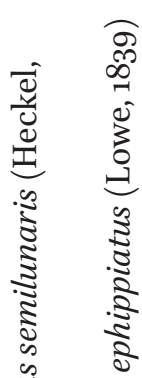

胥.

竎

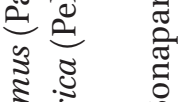

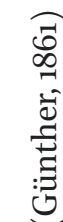

¿

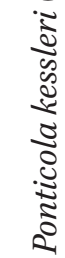

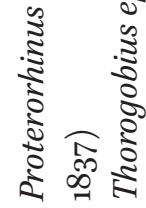

च

స్

芯节

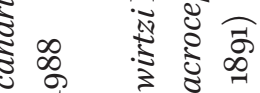

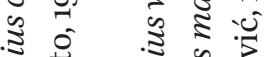

苟

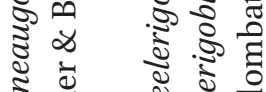

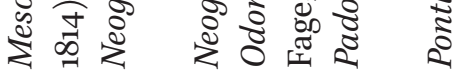

彭竞 


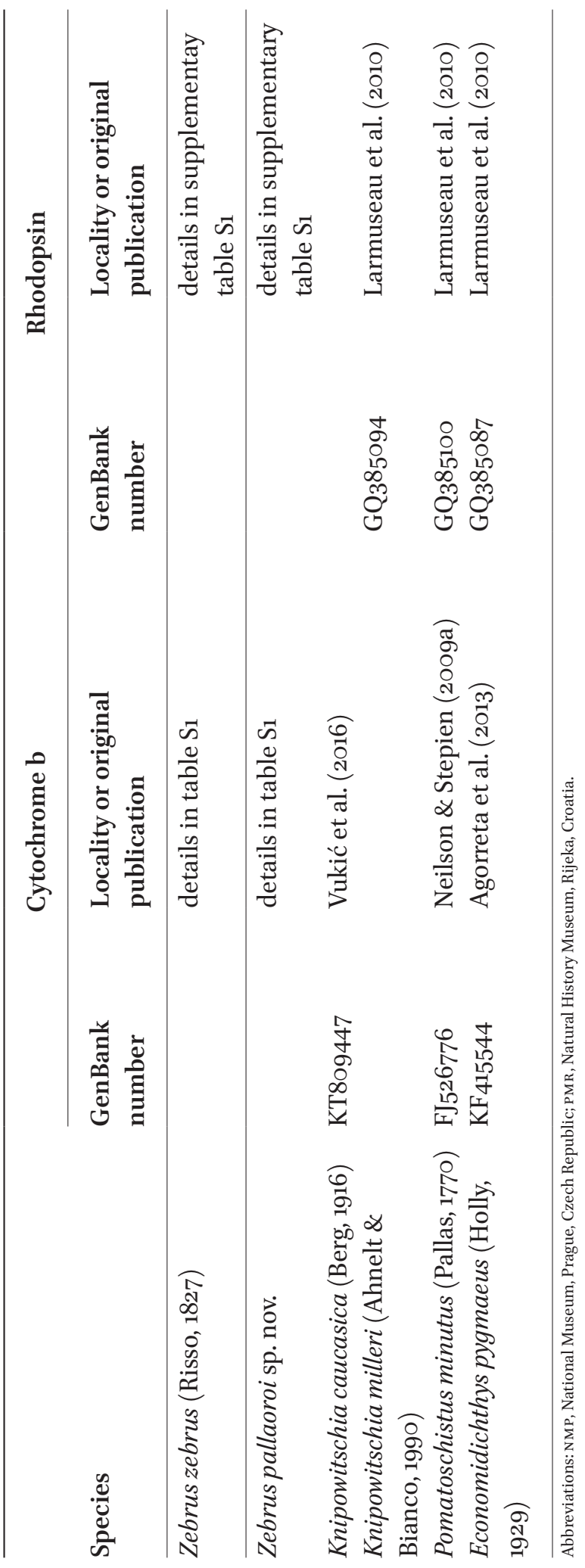


and $\mathrm{TRN}+\mathrm{I}+\mathrm{G}$, and $\mathrm{GTR}+\mathrm{I}+\mathrm{G}, \mathrm{TVM}+\mathrm{G}$ and TRNEF $+\mathrm{I}+\mathrm{G}$ for rhodopsin, and were applied for Bayesian Inference.

Phylogenetic relationships of Z. pallaoroi sp. nov. with other species included in the analyses were estimated with Bayesian Inference (BI) and Maximum Likelihood (ML) approaches, applying partitions by codon positions. For phylogenetic analyses, all individual haplotypes of both Zebrus species and M. macrocephalus, collapsed in FaBox (Villesen, 2007), were used. BI was conducted in MrBayes v3.2.2 (Ronquist et al., 2012) with four independent MCMC runs for 10 million generations for cytochrome $b$ and 3 million generations for rhodopsin. Trees were sampled every 1000 generations. Run convergence was analysed and visualized in TRACER v1.7.o. The first $25 \%$ of sampled trees were discarded as burn-in. The remaining trees were used to construct a 50\% majority-rule consensus tree. ML was assessed in Randomized Axelerated Maximum Likelihood (RAxML 8.2.12, Stamatakis, 2014) using the Science Gateway portal CIPREs (Miller et al., 2015). Model GTR $+\mathrm{G}$ was used for each partition. Support of each tree node was estimated by applying 1000 nonparametric bootstrap replicates. Genetic distances (uncorrected p-distances) between and within species of the Gobius-lineage were estimated with MEGA 6 (Tamura et al., 2013).

Haplotype networks for both Zebrus species and M. macrocephalus were constructed in PopART (Leigh \& Bryant, 2015), applying a statistical parsimony method (Clement et al., 200o). All sequences were used to construct the network. In the case of rhodopsin, both alleles of each individual were included.

The sampling complied with protocols approved by the responsible governmental authorities (according to the countries where the sampling was conducted).

\section{Results}

\section{Taxonomy}

Zebrus de Buen [F.] 1930

Zebrus (subgenus of Gobius) de Buen [F.] 1930:135, type species Gobius zebrus Risso 1827, by original designation, monotypy, and absolute tautonymy.

Description. The genus redescription was based on the genus description of Zebrus in Miller (1977) and adjusted to fit the new species and to include additional differences vs. genus Millerigobius: Body moderately elongate; eyes dorsolateral, with interorbital space 2.1-4.6 in eye-diameter; cranial roof covered by dorsal axial musculature; anterior nostril tubular, with a thin long tentacle on posterior rim; posterior nostril short tube adnate to the border of orbit; mouth oblique, with posterior angle below pupil; chin with small mental fold; teeth in both jaws erect, caniniform; upper jaw with enlarged outer row, intermediate irregularly scattered small teeth and two to four enlarged median posterior teeth; lower jaw with an outer row of larger teeth, intermediate irregularly scattered small teeth and a short inner row of enlarged teeth laterally ending with one to three distinct canine tooth on each side. Pectoral girdle without dermal flaps on anterior edge. Branchiostegal membrane attached along the entire lateral margin of isthmus, from immediately anterior to the pectoral margin. Pectoral fin with uppermost rays partially free from the membrane, pectoral-fin rays 16-18. Pelvic disc complete, rounded, posterior edge before anus; pelvic anterior membrane welldeveloped, without lateral lobes. Caudal fin rounded, shorter than the head. Body with ctenoid scales, 29-38 in lateral series; head and predorsal area naked; breast naked; uppermost and lowermost scales of caudal peduncle not enlarged. Cephalic lateral-line system with anterior and posterior oculoscapular and 
preopercular canals, with pores $\sigma, \lambda, \varkappa, \omega, \alpha, \beta, \rho$, $\rho^{1}, \rho^{2}$, and $\gamma, \delta, \varepsilon$, respectively. Seven transverse suborbital rows of sensory papillae; rows 1-4 in front of row $b$; rows 5 and 6 divided by row $b$ into upper and lower segments; row $5 i$ opposite to row $6 i$, row $6 i$ extending only by a few papillae below the level of row $d$, row 7 above row $b$; row $b$ ends anteriorly below eye, near row 4 and posteriorly distant from pore $\delta$; anterior oculoscapular row $x^{1}$ ends anteriorly well behind pore $\beta$, opposite row $z$; row $g$ not extending anteriorly beyond lateral ends of row $o$; snout with four median preorbital rows; no interorbital papillae. Broad pale transverse stripe across anterior nape behind eyes, if present, does not include posterior part of eyes. Vertebrae (including urostyle) 27-28 (precaudal + caudal vertebrae: $10+17-18$ ) in presently studied material, 26-27 according to Miller (1977); dorsal pterygiophore formula 3-2211o.

\section{Key to Zebrus species}

1a. Left and right ventrolateral head ridges transversally connected on the anterior part by the short transversal ridge; snout longer than eye, its length 1.1-1.2 of eye diameter; posterior nostril short tube, 4/5-9/10 of anterior nostril; eyes moderately small, eye diameter is $4.3^{-4.7}$ in head length; anterior membrane in midline depth about $2 / 3$ of spinous ray; body with 10-11 vertical dark brown bands present along lateral side, first in front of the first dorsal fin, last at the end of the second dorsal fin, at upper edge about equal or narrower than pale interspaces between Zebrus pallaoroi sp. nov. 1b. Left and right ventrolateral head ridges disconnected anteriorly by midventral flat area; snout shorter than eye, its length o.8-0.9 of eye diameter; posterior nostril 1/4-2/5 of anterior nostril; eye diameter is 3.1-4.1 in head length; anterior membrane in midline depth about $1 / 2$ of spinous ray; $6-9$ dark vertical stripes broader or equal to pale interspaces .Z. zebrus

\section{Zebrus pallaoroi Kovačić, Šanda \& Vukić} sp. nov.

Holotype (fig. 1A). Male, 31.81 + 8.51 mm, NMP P6V 144302, Kostanjica, Boka Kotorska, Adriatic Sea, Montenegro, 24 August 2016, 42.485139 ${ }^{\circ} \mathrm{N}, 18.670347^{\circ} \mathrm{E}$, collector Šanda R. Paratypes. Male, $27.72+6.83 \mathrm{~mm}$, NMP P6V 144300 , and female, $26.44+6.39 \mathrm{~mm}$, NMP P6V 144303, the same data as holotype.

Diagnosis. Zebrus pallaoroi sp. nov. differs from the only congeneric species, $Z$. zebrus by each of the following characters: (1) snout longer than eye, its length 1.1-1.2 of eye diameter; (2) posterior nostril short tube, about $0.8-0.9$ of anterior nostril (fig. 2A); (3) eyes moderately small, eye diameter is $4.3-4.7$ in head length; (4) left and right ventrolateral head ridges transversally connected on anterior part by short transversal ridge (fig. $2 \mathrm{C}$ ), (5) anterior membrane in midline depth about $2 / 3$ of spinous ray (fig. 2B); (6) head canal pores large, pore $\alpha$ diameter about half of the distance between pore $\rho$ and $\rho^{1}$; (7) suborbital sensory papillae row $5 i$ going downwards to or near the level of row $d$, distance between row $5 i$ and row $d$ absent or much smaller than length of row $5 i$; (8) body with ten to eleven vertical dark brown bands present along lateral side, first in front of the first dorsal fin, last at end of the second dorsal fin, at upper edge about equal or narrower than pale interspaces inbetween.

Description (all morphometric values and meristics in the text are presented as holotype first and paratypes, if different, in parentheses; first the male paratype, then female). General morphology (fig. 1A): Body proportions are given in table 2 . Body elongate, its 
TABLE 2 Morphometric characters (as proportional measurements in \%) of Zebrus pallaoroi sp. nov.

\begin{tabular}{|c|c|c|c|}
\hline Specimen & $\begin{array}{l}\text { P6V } 144302 \\
\text { holotype }\end{array}$ & $\begin{array}{l}\mathrm{P} 6 \mathrm{~V} 144300 \\
\text { paratype }\end{array}$ & $\begin{array}{l}\text { P6V } 144303 \\
\text { paratype }\end{array}$ \\
\hline Sex & male & male & female \\
\hline $\begin{array}{l}\text { Standard length }(\mathrm{SL}) \text { in } \mathrm{mm} \\
\% \text { of standard length }\end{array}$ & 31.81 & $27 \cdot 72$ & 26.44 \\
\hline 1st spine length of first dorsal fin & 10.0 & 12.6 & 12.2 \\
\hline 2nd spine length of first dorsal fin & 11.8 & $13 \cdot 5$ & 12.7 \\
\hline 3 rd spine length of first dorsal fin & 12.7 & 14.4 & $14 \cdot 3$ \\
\hline 4th spine length of first dorsal fin & 12.2 & 14.0 & $13 \cdot 3$ \\
\hline $5^{\text {th }}$ spine length of first dorsal fin & 12.1 & 12.8 & 11.5 \\
\hline 6th spine length of first dorsal fin & $7 \cdot 9$ & 9.0 & 8.2 \\
\hline Anal fin base & 19.0 & $19 \cdot 7$ & 18.8 \\
\hline Anal fin spine length & $7 \cdot 7$ & 8.2 & 8.4 \\
\hline Body depth at anal fin origin & 18.2 & 16.8 & 17.0 \\
\hline Body depth at pelvic fin origin & 18.9 & 18.4 & 18.6 \\
\hline Body width at anal fin origin & 12.5 & 11.7 & 11.6 \\
\hline Body width at pelvic fin origin & $17 \cdot 7$ & 18.4 & 17.6 \\
\hline Caudal fin length & 26.8 & 24.6 & 24.2 \\
\hline Caudal peduncle depth & 12.6 & 12.7 & 10.7 \\
\hline Caudal peduncle length & 21.0 & 20.2 & 18.9 \\
\hline Eye diameter & $7 \cdot 7$ & 7.0 & 6.7 \\
\hline First dorsal fin base & 13.1 & $13 \cdot 4$ & 14.2 \\
\hline Head depth & $15 \cdot 7$ & $17 \cdot 5$ & 14.6 \\
\hline Head length & 28.5 & 31.2 & 29.0 \\
\hline Head width & $25 \cdot 5$ & 26.0 & 23.9 \\
\hline Pectoral fin length & $29 \cdot 9$ & 26.0 & 26.1 \\
\hline Pelvic fin length & 21.0 & 20.9 & 20.7 \\
\hline Pelvic to anus & 26.2 & 24.8 & 27.2 \\
\hline Second dorsal fin base & 30.8 & $27 \cdot 5$ & 26.4 \\
\hline Second dorsal fin spine length & 11.3 & $13 \cdot 3$ & 11.0 \\
\hline Snout to origin of first dorsal fin & 36.0 & 37.2 & 37.0 \\
\hline Snout to origin of second dorsal fin & 56.3 & 56.8 & 56.8 \\
\hline Snout to vertical of anal fin origin & 61.2 & 61.1 & 61.3 \\
\hline Snout to vertical of anus & $5^{8.5}$ & $5^{6.5}$ & 56.4 \\
\hline $\begin{array}{l}\text { Snout to vertical of pelvic fin origin } \\
\% \text { of caudal peduncle }\end{array}$ & $31 \cdot 3$ & 31.0 & $29 \cdot 5$ \\
\hline $\begin{array}{l}\text { Caudal peduncle depth } \\
\% \text { of head length }\end{array}$ & $59 \cdot 9$ & 62.6 & 56.8 \\
\hline Cheek depth & 27.1 & 22.5 & 22.9 \\
\hline Eye diameter & 23.2 & 21.4 & 21.7 \\
\hline Head depth & 55.2 & $5^{6.1}$ & $5^{0.1}$ \\
\hline Head width & $89 \cdot 5$ & 83.4 & 82.2 \\
\hline Postorbital length & $55 \cdot 3$ & 56.6 & $57 \cdot 4$ \\
\hline Snout length & 26.8 & 23.9 & 26.0 \\
\hline
\end{tabular}


TABLE 2 Morphometric characters (as proportional measurements in \%) of Zebrus pallaoroi sp. nov. (Cont.)

\begin{tabular}{llll}
\hline Specimen & $\begin{array}{l}\text { P6V 144302 } \\
\text { holotype }\end{array}$ & $\begin{array}{l}\text { P6V144300 } \\
\text { paratype }\end{array}$ & $\begin{array}{l}\text { P6V 144303 } \\
\text { paratype }\end{array}$ \\
\hline Sex & male & male & female \\
\hline $\begin{array}{l}\text { \% of eye diameter } \\
\text { Interorbital width }\end{array}$ & 51.4 & & \\
$\begin{array}{l}\text { \% of pelvic to anus } \\
\text { Pelvic fin length }\end{array}$ & 80.3 & 49.7 & 51.5 \\
\hline
\end{tabular}

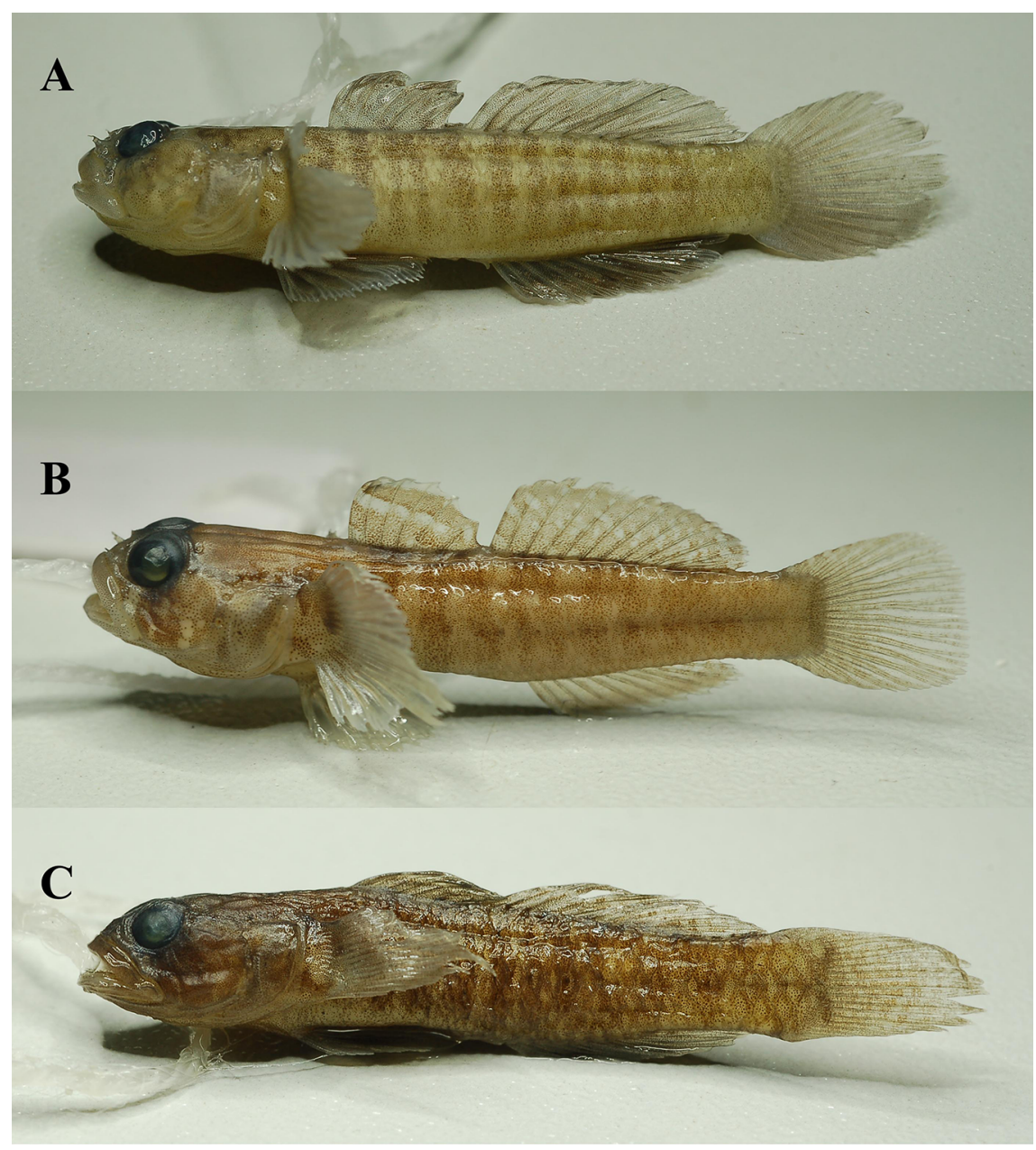

Preserved specimens. (A) Zebrus pallaoroi sp. nov., NPM P6V144302, holotype, male, $31.81+8.51 \mathrm{~mm}$, Kostanjica, Boka Kotorska, Adriatic Sea, Montenegro. Photo by M. Kovačić. (B) Zebrus zebrus, NMP P6V 140912, neotype, female, 23.25 + 6.22 mm, îll Gross, Banyuls sur Mer, France (C) Millerigobius macrocephalus, NMP P6V 142686, juvenile of unidentified sex, 14.28 + 3.97 mm, îll Gross, Banyuls sur Mer, France. 
depth at pelvic-fin origin $5.3(5.4)$ in $\mathrm{SL}$, at anal-fin origin $5.5(5.9)$ in SL, laterally compressed posteriorly, with deep caudal peduncle, caudal peduncle depth o.6 of caudal peduncle length (fig. 1A). Head moderately large, the length 3.5 (3.2 and 3.4) in SL, width 3.9 (3.8 and 4.2) in SL, depth 6.4 (5.7 and 6.9) in SL, and depressed, its depth 1.6 (1.5 and 1.6) in width. Snout oblique, with a convex ridge along dorsal midline visible only in paratypes, longer than eye, its length 1.2 (1.1 and 1.2) of eye diameter, 3.7 (4.2 and 3.8) in head length. Anterior nostril nasal tube with a single process from the posterior rim, posterior nostril short tube, $81 \%$ ( 85 and $88 \%$ ) of the anterior nostril (fig. 2A). Eyes dorsolateral, moderately small, eye diameter is 4.3 (4.7 and 4.6) in head length, slightly elevated above the

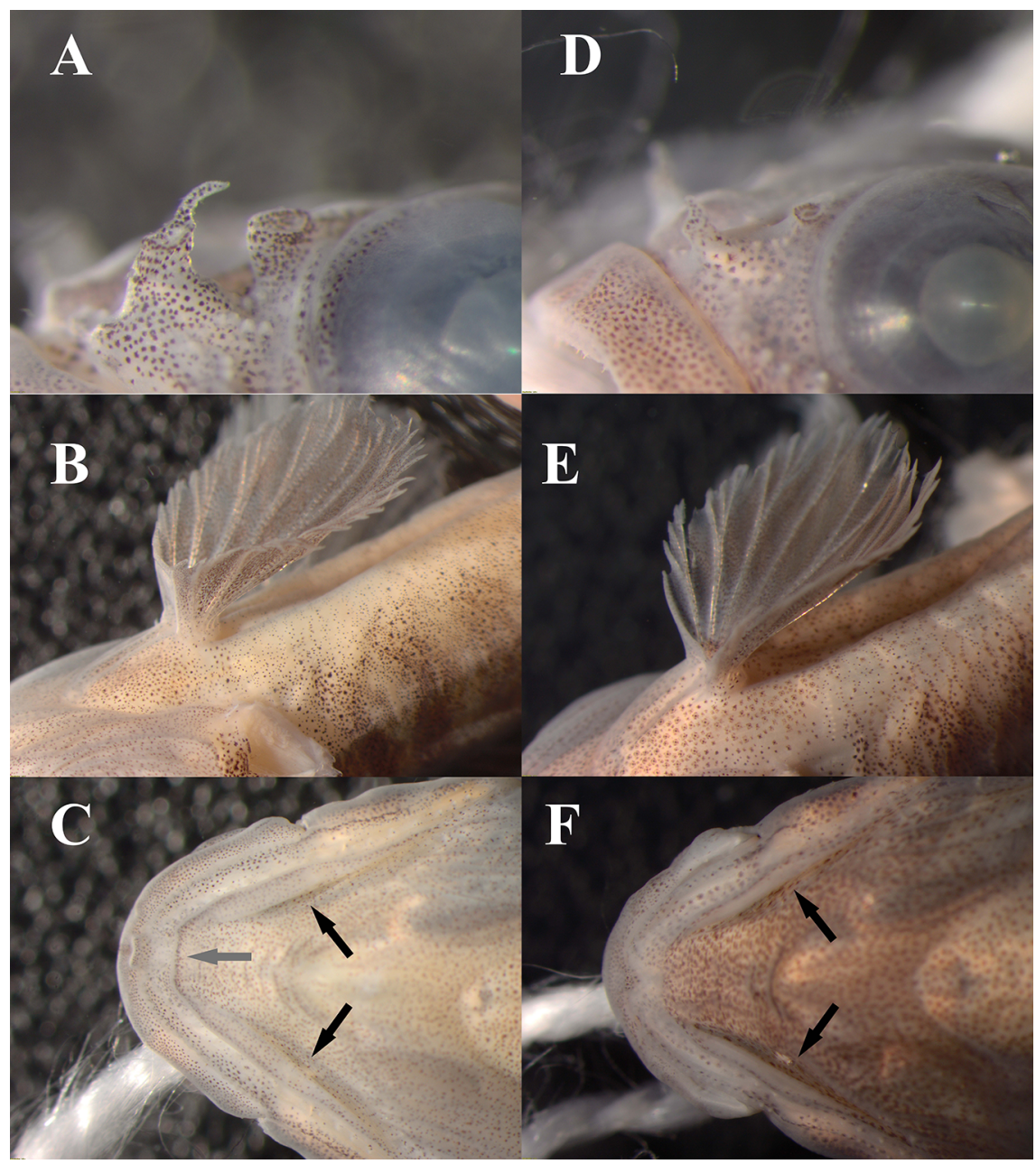

Zebrus pallaoroi sp. nov. NMP P6V 14430o, paratype, male, 27.72 + 6.83 mm, Kostanjica, Boka Kotorska, Adriatic Sea, Montenegro: (A) posterior and anterior nostrils; (B) pelvic fin with anterior membrane; (C) ventrolateral head ridges marked with black arrows and transversal connection marked with a grey arrow, small mental fold visible at the lower lip, anteriorly from the transversal connection of ventrolateral ridges. Zebrus zebrus: NMP P6V 142593, male, 21.84 + 5.6 mm, Selce, Kvarner area, Croatia: (D) posterior and anterior nostrils; (E) pelvic fin with anterior membrane; (F) ventrolateral head ridges marked with black arrows.

PHOTOS BY M. KOVAČIĆ. 
dorsal profile. Interorbital moderately narrow, $1 / 2$ of eye diameter. Cranial roof covered by dorsal axial musculature. Predorsal area about horizontal. Mouth oblique, jaws ending anteriorly nearly equally to lower lip. Upper lip broad, width nearly uniform, more or less as wide as the lateral preorbital area in female, wider in males. Mouth moderately large, posterior angle of jaws ending posteriorly below mideye. Cheek relatively narrow. Teeth in both jaws erect, caniniform; upper jaw with enlarged outer row, intermediate irregularly scattered small teeth and four enlarged median posterior teeth; lower jaw with an outer row of larger teeth, intermediate irregularly scattered small teeth and a short inner row of enlarged teeth laterally ending with one or two distinct canine teeth on each side. Tongue reduced. Chin with a small mental fold. Left and right ventrolateral head ridges transversally connected on the anterior part by a short transversal ridge (fig. 2C). Branchiostegal membranes fused to isthmus along the entire lateral margin of the isthmus, from immediately anterior to pectoral margin, gill openings restricted to pectoral-fin base. No spines on preopercle. Pectoral girdle without dermal flaps on anterior edge.

Fins. First dorsal fin VI, second dorsal fin I+10 (I+1O-11); anal fin I+8 (I+8-9); branched caudal-fin rays 16 (15), segmented 18 (17), pectoral-fin rays 17 left fin, right fin cut (in all type material), pelvic fins $\mathrm{I}+5 / 5+\mathrm{I}$. Fin morphometrics in proportion to standard body length given in table 2. Spines of first dorsal fin not elongate or filamentous, spines II-V about equal, the third spine longest; spines V and VI of first dorsal fin reaching the origin of the second dorsal fin when folded down. Origin of first dorsal fin behind vertical at the pectoral-fin base. Interdorsal space with a well-developed membranous connection between dorsal fins. The second dorsal fin originates above the anus in the female and above urogenital papilla in males, with the longest rays hardly reaching the base of uppermost caudal-fin rays in males, and not reaching in the female. Origin of anal fin below vertical of the first segmented ray of the second dorsal fin in males, or second in the female. Anal fin with last ray origin below penultimate ray of the second dorsal fin in the female, below third from the end in males. Posterior tip of anal fin not reaching the base of lowermost caudal-fin rays. Pectoral-fin rays all branched. Pectoral fin with three uppermost rays bifid, partially free from the membrane, and three more with shorter free tips, first ray free tip o.6-0.7 of entire first ray length. Pectoral fins nearly extending posteriorly to below origin of the second dorsal fin. Pelvic fins disc complete, rounded, with ray 5 longest, all rays branched, anterior membrane well-developed, in midline depth about $2 / 3$ (exactly $65-68 \%$ in the type material) of spinous ray and without lateral lobes, but with tips of spinous ray merely visible (fig. $2 \mathrm{~B}$ ). Pelvic fins posterior edge before anus in both sexes. Caudal fin rounded, shorter than the head, 1.1 (1.2 and 1.3) in head length.

Scales. Body with ctenoid scales. Scales in lateral series 32 (male paratype 32 , female paratype left 33 and right side damaged for the count) left, with one more row of small scales on caudal fin; in transverse series 11 (male paratype left 10 and 11 right side, female paratype 10); circumpeduncular scales 12. Head with cheek and opercle naked. Predorsal area and first dorsal fin base naked to the last spine, with the upper edge of the scaled area from behind upper part of pectoral axilla backward and up to the last first dorsal-fin spine. Prepectoral and breast naked. Belly naked anteriorly, with cycloid scales posteriorly and laterally. Uppermost and lowermost scales of caudal peduncle not enlarged. 


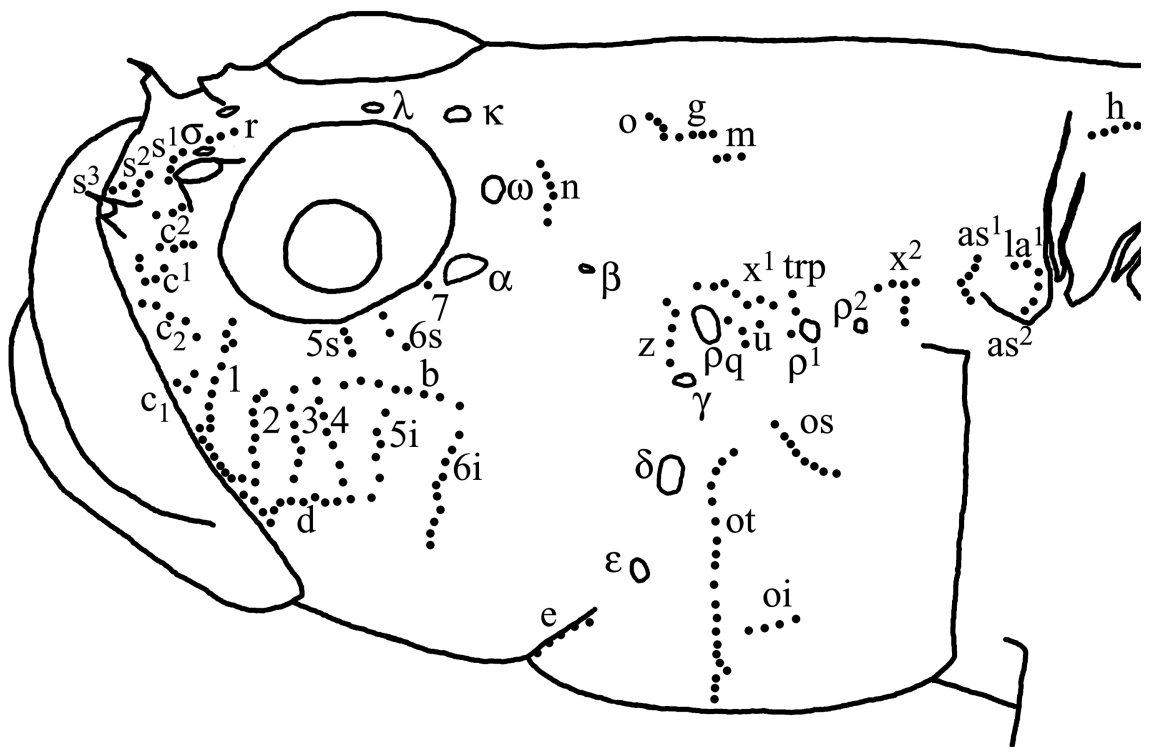

FIGURE 3 Zebrus pallaoroi sp. nov. NMP P6V 144302, holotype, male, $31.81+8.51$ mm, Kostanjica, Boka Kotorska, Adriatic Sea, Montenegro: head lateral line sensory papillae and canal pores. DRAWING BY M. KOVAČIĆ.

Lateral line system (fig. 3). Head with anterior and posterior oculoscapular canals and preopercular canal with pores $\sigma, \lambda, \varkappa, \omega, \alpha, \beta, \rho, \rho^{1}$, $\rho^{2}$, and $\gamma, \delta, \varepsilon$, respectively. Pores large, with pore $\alpha$ diameter about half of the distance between pore $\rho$ and $\rho^{1}$. Rows of head sensory papillae were counted on all type material. Preorbital rows: snout with four median preorbital series, upper row $r$ (3) middorsally from pore $\sigma$ and above posterior nostrils, $s^{1}(3-4)$ at posterior nostril, row $s^{2}(2-3)$ at anterior nostril, and vertical row $s^{3}(2)$ above the upper lip. Lateral series $c$ in four parts: superior $c^{2}(3+3-3+4)$ as two rows between the posterior nostril and anterior nasal tube, middle $c^{1}\left(5^{-6}\right)$ as two rows or as a cluster of papillae just below the base of the anterior nasal tube, inferior rows: upper horizontal $c_{2}\left(5^{-6}\right)$ above the upper lip and lower horizontal $c_{1}$ (3) between the upper lip and row 1. Suborbital rows: no row $a$. Row $b$ (8) longitudinal, short, ends anteriorly near row 4 and below pupil or pupil posterior edge and posteriorly distant from pore $\delta$. Seven transverse suborbital rows of sensory papillae, four suborbital rows in front of row $b$, three above row $b$, two transverse suborbital rows below row $b$. Row 1 vertical, upper edges of rows $2-5$ in the level and close to orbit in the female paratype or, in the holotype and male paratype, rows 2-4 well separated from the lower border of orbit, row 5 divided by row $b$ into upper $(5 s)$ and lower segments $(5 i)$, row $5 i$ going downwards to or near the level of row $d$, the distance between row $5 i$ and row $d$ absent or much smaller than the length of row $5 i$, row $5 i$ opposite row $6 i$, row 6 above and below row $b$, row $6 i$ extending for a few papillae below the level of row $d$,row 7 aboverow $b$, at pore $\alpha(1: 8-10$, 2: 6-8, $3: 6-7,4: 7-9,5: 3+5$ and $4+4,6: 3+10$ and $4+9,7: 1)$. Row $d(18-22)$ with supralabial part and the part on cheek connected, ending backward below posterior part of the eye. Preoperculo-mandibular rows: external row $e(21+14-26+16)$ and internal row $i(8+7-$ $10+9)$ divided into anterior and posterior sections, mental row $f$ longitudinal (4-7). 
Oculoscapular rows: anterior longitudinal row $x^{1}(7-10)$ ends anteriorly well behind pore $\beta$, posterior longitudinal row $x^{2}(3-4)$ above the opercular edge, transversal row $z\left(5^{-7}\right)$ below the posterior end of anterior oculoscapular canal, ends close to row $x^{1}$, transversal row $q$ $(2-4)$ behind pore $\rho$ and below longitudinal row $u(2)$, transversal row trp (3) behind row $x^{\prime}$, transversal row $y(2-3)$ below row $x^{2}$. Axillary vertical rows $a s^{1}\left(5^{-8}\right), a s^{2}\left(5^{-8}\right)$, and $a s^{3}\left(3^{-5}\right)$ and horizontal rows $l a^{1}(2-3)$ and $l a^{2}(1-3)$ present, row $l a^{2}$ not visible in female paratype. Opercular rows: transverse row ot (16-20), superior longitudinal row os (6-8), and inferior longitudinal row oi (3-5). Anterior dorsal rows: anterior transverse row $n(6-8)$ behind pore $\omega$, transverse row $o(3-4)$ distant to the fellow in the dorsal midline, longitudinal row $g(3-4)$ not extending anteriorly beyond lateral ends row $o$, longitudinal row $m(2-3)$ behind below row $g$, longitudinal row $h(7-8)$ in front of the first dorsal fin anterior origin, continuous in the holotype and female paratype and divided in the male paratype. Interorbital papillae absent.

Colouration. Live colouration not documented. Colour preserved (fig. 1A). Head and body pale yellow to white brown (beige to tan), with dotted dark brown markings of larger and smaller melanophores shaping the patterns. Body with ten to eleven vertical dark brown bands present along lateral side, first in front of the first dorsal fin, last at end of the second dorsal fin. The dark vertical bands are at the upper edge about equal or narrower than paler interspaces in-between. Reticulate pattern, formed by dark markings along the scale margins also visible, better in paratypes. Caudal peduncle is more uniformly and less intensively coloured. Dorsal view also striped, no pale saddle shapes on the back. Ventral bodyside, including belly whitish, more dotted in males than in the female. Head variably dotted, with broad pale transverse stripe across anterior nape behind eyes, not including eyes, curving backward and downwards, less recognizable on opercles and well visible again on pectoral fin lobes. Posteriorly to the transverse stripe nape and predorsal area dark dotted, marbled in males, uniformly dotted in the female. The sides of the head marbled in males, uniformly dotted in the female with an anterior oblique dark band from eye to the upper lip. Snout pigmented. Eyes dark, with a grey pupil. The underside of the head and breast pigmented by fine dots in both sexes, with only anterior isthmus paler, especially in the female. Pectoral fin lobe with the broad pale oblique area and dark upper and lower corners. The dark basal pectoral mark short, restricted to the upper six rays, and the pigmented area across the entire base of pectoral rays poorly defined. The rest of the pectoral fin uniformly pigmented in males, only the basal half pigmented in the female. The first dorsal fin entirely dotted, with two hardly recognizable oblique bands of more intensive pigmentation start at the first spine at middle and at the upper part, and going backward and downward from it, the second dorsal and anal fins dotted with no recognizable pattern in both sexes, less intensively at base of rays. Caudal fin more or less uniformly dotted. Pelvic fin uniformly pigmented in males, only basal and inner part and anterior membrane pigmented in the female.

Osteology. Vertebrae (including urostyle) 27 (precaudal + caudal vertebrae: $10+17$ ); dorsal pterygiophore formula 3-22110.

Etymology. Named in honour of Armin Pallaoro, a great ichthyologist from the Institute of Oceanography and Fishery Split, Croatia, who sadly passed away in January 2020. Armin unselfishly shared his knowledge and his fieldwork and laboratory skills on 
fishes with generations of younger Croatian colleagues at their beginnings, including one of the authors (MK).

Ecology. The types and the additional specimens were found between gravel and small boulders in very shallow infralittoral waters, just by the shore, at a maximum depth of $1 \mathrm{~m}$. This species is a typical cryptobenthic fish.

Geographical distribution. Recorded in the southern part of the Adriatic Sea, the northern part of the Ionian Sea, and the northern and western part of the Aegean Sea (fig. 4).

Remarks. At present, the genus Zebrus includes just two species: Z. pallaoroi sp. nov. and Z. zebrus. Zebrus pallaoroi sp. nov. differs in various characters from Z. zebrus (based on comparative material and Miller (1977)) as followed: snout longer than eye, its length 1.1--1.2 of eye diameter vs. snout shorter than eye (Miller, 1977), its length o.8-0.9 of eye diameter in Z. zebrus (comparative material); posterior nostril short tube, 4/5-9/10 of anterior nostril vs. posterior nostril about $1 / 2$ of anterior nostril reported by Miller (1977), 1/4-2/5 of anterior nostril found in comparative material of Z. zebrus (fig. $2 \mathrm{~A}$, $\mathrm{D})$; eyes moderately small, eye diameter is
4.3-4.7 in head length vs. eye diameter is 3.4-4.1 in head length (Miller, 1977), 3.1-4.1 in head length (comparative material) in Z. zebrus; left and right ventrolateral head ridges transversally connected on anterior part by short transversal ridge vs. left and right ventrolateral head ridges disconnected anteriorly by midventral flat area in $Z$. zebrus (fig. $2 \mathrm{C}$ and $\mathrm{F}$ ) (comparative material, no data in Miller, 1977, the transversal connection of ventrolateral head ridges should not be confused with the small mental fold placed more anterior on chin below lower lip that is present in Z. pallaoroi and is of variable occurrence in $Z$. zebrus; both structures visible in fig. $2 \mathrm{C}$ ); anterior membrane in midline depth about $2 / 3$ of spinous ray vs. about $1 / 2$ of spinous ray reported in Miller (1977) and 1/4-1/2 of spinous ray found on comparative material of Z. zebrus (fig. $2 \mathrm{~B}$ and $\mathrm{E}$ ); head canal pores large, pore $\alpha$ diameter about half of the distance between pore $\rho$ and $\rho^{1}$ vs. head canal pores of moderate size, distance between pore $\rho$ and $\rho^{1}$ about three times or more longer than pore $\alpha$ diameter (comparative material, no data in Miller, 1977) in Z. zebrus; suborbital sensory papillae row $5^{i}$ going downwards to or near the level of row $d$, distance between

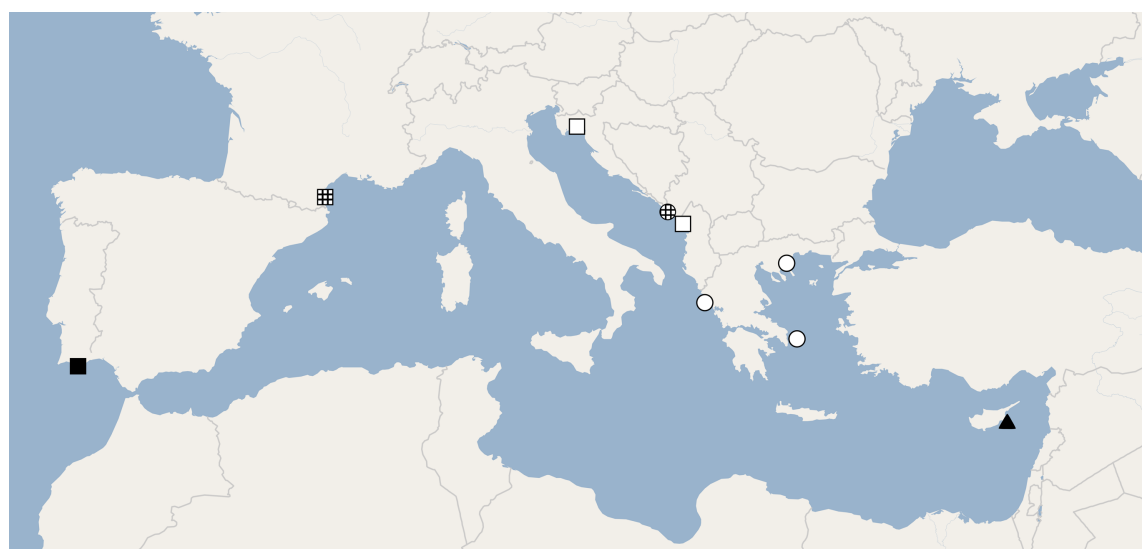

FIGURE 4 Map of sampling localities of Zebrus pallaoroi sp. nov. (circle) and Z. zebrus (square). The type locality of $Z$. pallaoro $i$ and locality of neotype of $Z$. zebrus are marked with hatching. The westernmost record of $Z$. zebrus is indicated by $\mathbf{m}$. The first record of Millerigobius macrocephalus from Cyprus is indicated by $\boldsymbol{\Lambda}$. 
row $5 i$ and row $d$ absent or much smaller than length of row $5 i$ vs. suborbital sensory papillae row $5 i$ ends downwards distant from row $d$, row $5 i$ length equal or smaller than distance between row $5 i$ and row $d$ (comparative material, no data in Miller, 1977) in Z. zebrus; body with 10-11 vertical dark brown bands present along lateral side, first in front of the first dorsal fin, last at end of the second dorsal fin, at upper edge about equal or narrower than pale interspaces inbetween vs. 6-9 dark vertical stripes at upper edge, broader or equal than pale interspaces in Z. zebrus (Miller, 1977 and comparative material). In addition to these differences, the new species has a longer and more slender body which results in body depth at pelvic-fin origin 5.3 (5.4) in SL vs. body depth at pelvic-fin origin 4-4.7 in SL in the comparative material of Z. zebrus. However, Miller (1977) reported a different range of body depth at the pelvic-fin origin in SL for Z. zebrus (4.4-5.5) which overlaps with the new species.

\section{The designation of Zebrus zebrus}

(Risso, 1827) neotype

Rationale. Based on morphological and genetic data presented here, the genus Zebrus includes two species. Until now, the genus was considered monotypic (Miller, 1977). The original description of Zebrus zebrus (decribed as Gobius zebrus) by Risso (1827) is only general, and does not include any morphological characteristics which could unambiguosly determine which of the two currently recognised species was included under the name. Furthermore, no original type material exists (Fricke et al., $2 \mathrm{O} 2 \mathrm{Ob}$ ) to prove the identity of $Z$. zebrus by type inspection. To resolve this taxonomic problem, we here designate a neotype for this species. The designated neotype was selected from available specimens analysed in this study to originate as close to the locus typicus
(Nice, France) as possible, and is accessible by the voucher number NMP P6V 140912 at the NMP. The neotype of Z. zebrus was designated fulfilling the qualifying conditions set by ICZN (1999) as follows: The description of the second species of Zebrus in the hitherto monotypic genus represented an exceptional need for the designation of a neotype for the first Zebrus species (Article 75.3, ICZN, 1999). The genus Zebrus represents the complex zoological problem (Article 75.2, ICZN, 1999) of morphologically very similar congenerics. Therefore, in addition to the diagnosis, the designation of a neotype is needed to have the name-bearing material of this species in addition to the type material of the new species. This complex zoological problem (Article 75.2, ICZN, 1999) could become even more complicated if more lineages within the Zebrus/Millerigobius clade would be found. In that case, the name-bearing material of the present species, holotype and neotype, should be available for comparison with the new material. The purpose was to clarify the taxonomic status of two species (Article 75.3.1, ICZN, 1999). The diagnostic characters are stated in the diagnosis (Article 75.3.1, ICZN, 1999), which is sufficient to ensure the recognition of the species (Article 75.3.3, ICZN, 1999). We are positive that no name bearing type specimens exist for Z. zebrus (Fricke et al., 2O2Ob; Article 75.3.4, ICZN, 1999). The neotype fits the species redescription of $Z$. zebrus (Miller, 1977; Article 75.3.5, ICZN, 1999) and the neotype was collected relatively close to the original type locality (see locality of the neotype material, Article 75.3.6, ICZN, 1999). The neotype was stored in a public scientific museum collection (see storage of the neotype material, Article 75·3.7, ICZN, 1999).

Neotype. NMP P6V 140912, female, $23.25+6.22 \mathrm{~mm}$, Îll Gross, Banyuls sur Mer, France; $42^{\circ} 28^{\prime} 55 \cdot 5^{\prime \prime} \mathrm{N} \quad 3^{\circ} 8^{\prime} 12.96 " \mathrm{E}$, coll. R. Šanda, 14 October 2011 (fig. 1b). 
Additional material examined. NMP P6V 142530, female, 25.21 $+6.18 \mathrm{~mm}$, Sv. Marak, Krk Island, Croatia; NMP P6V 142592, female, $21.9+5.58 \mathrm{~mm}$, NMP P6V 142593, male, $21.84+5.6 \mathrm{~mm}$, NMP P6V 142594, male, ${ }_{18.76}+4.76 \mathrm{~mm}$, NMP P6V 142595, female, $19.59+4.95 \mathrm{~mm}$, NMP P6V 142596, female, $19.39+4.85 \mathrm{~mm}$, NMP P6V 142597, male, $21.16+5.58 \mathrm{~mm}$, NMP P6V 142598, female, $19.83+4.81 \mathrm{~mm}$, NMP P6V 142599, male, $21.91+5.65 \mathrm{~mm}$, all eight from Selce, Kvarner area, Croatia; NMP P6V 145212, male, $27.38+6.84 \mathrm{~mm}$, NMP P6V 145213, female, $26.48+6.44 \mathrm{~mm}$, NMP P6V 145214, female, $25.99+6.05 \mathrm{~mm}$, NMP P6V 145215, male, $27.11+6.45 \mathrm{~mm}$, NMP P6V 145216, male, $27.17+6.59 \mathrm{~mm}$, NMP P6V 145217, male, $27.8+7.17$, NMP P6V145218, male, 27.52+7.17 mm, NMP P6V 145219, male, $25.55+6.03 \mathrm{~mm}$, NMP P6V 145220, male, $27.57+7.03 \mathrm{~mm}$, all nine from Kamenjak, Krk Island, Croatia; NMP P6V 145287, female, $27.36+6.4 \mathrm{~mm}$, NMP P6V 145288, male, 25.73 + 6.o7 mm, NMP P6V 145289, male, $25.41+5.7 \mathrm{~mm}$, NMP P6V 14529o, male, $25.53+6.1 \mathrm{~mm}$, all four from Selce, Kvarner area, Croatia; NMP P6V 89017, male, $28.12+6.78 \mathrm{~mm}$ and NMP P6V 89018, female, $21.73+5.42 \mathrm{~mm}$, both from Punta Glavina, Krk Island, Croatia.

Diagnosis. Z. zebrus differs from the only congeneric species, Z. pallaoroi sp. nov. by each of the following characters: (1) snout shorter than eye, its length $0.8-0.9$ of eye diameter; (2) posterior nostril 1/4-2/5 of anterior nostril (fig. 2D); (3) eye diameter is 3.1-4.1 in head length; (4) left and right ventrolateral head ridges disconnected anteriorly by midventral flat area (fig. $2 \mathrm{~F}$ ), (5) anterior membrane in midline depth $1 / 4-1 / 2$ of spinous ray (fig. $2 E$ ); (6) head canal pores of moderate size, distance between pore $\rho$ and $\rho^{1}$ about three times or more longer than pore $\alpha$ diameter; (7) suborbital sensory papillae row $5 i$ ends downwards distant from row $d$, row $5 i$ length equal or smaller than distance between row $5 i$ and row $d$; (8) body with 6-9 dark vertical stripes at upper edge, broader or equal than pale interspaces.

\section{Molecular results}

A total of seven specimens of Z. pallaoroi sp. nov. were revealed among samples originally identified as Z. zebrus. All specimens of $Z$. pallaoroi sp. nov., $5^{8}$ specimens of $Z$. zebrus, and 14 specimens of $M$. macrocephalus were genetically analysed. All specimens were used for cytochrome $b$. The alignment of cytochrome b had a final length of $1117 \mathrm{bp}$. For rhodopsin analyses, seven specimens of Z. pallaoroi sp. nov., 13 of Z. zebrus, and 12 of $M$. macrocephalus were used. The alignment of rhodopsin sequences for the three species was $808 \mathrm{bp}$ long, and was used for haplotype network reconstruction. The length of the rhodopsin alignment, which included sequences of other goby species and was used for BI and ML analyses, was $740 \mathrm{bp}$.

Both molecular markers showed that Z. pallaoroi sp. nov. belongs to the group Zebrus/Millerigobius, which forms a well-supported and very distinct clade within the analysed species of gobies (figs 5,6 , supplementary figs $\mathrm{S}_{1}, \mathrm{~S}_{2}$ ).

The relationships between the species within the Zebrus/Millerigobius clade were not resolved and the topologies were not consistent for both markers and for both employed phylogenetic methods. While BI analysis of cytochrome b suggests a possible sister position of Z. zebrus and Z. pallaoroisp. nov., though not well-supported (posterior probability 0.53 , not shown in fig. 5 ), the ML analysis (supplementary fig. S1) suggests a possible sister relationship of $M$. macrocephalus and Z. zebrus, though again with very low statistical support ( $59 \%$, value not shown in supplementary fig. S1). A similar situation 


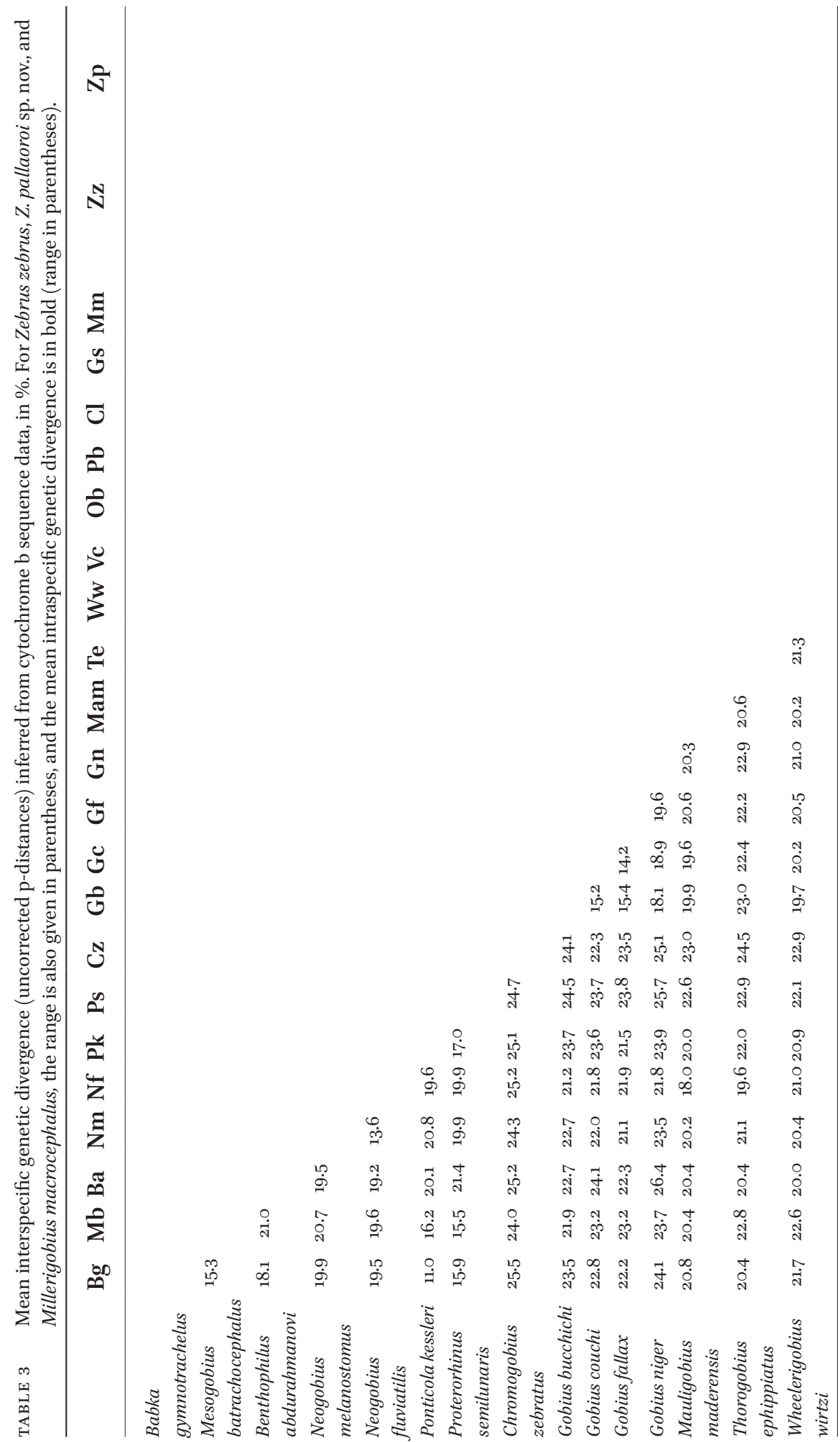




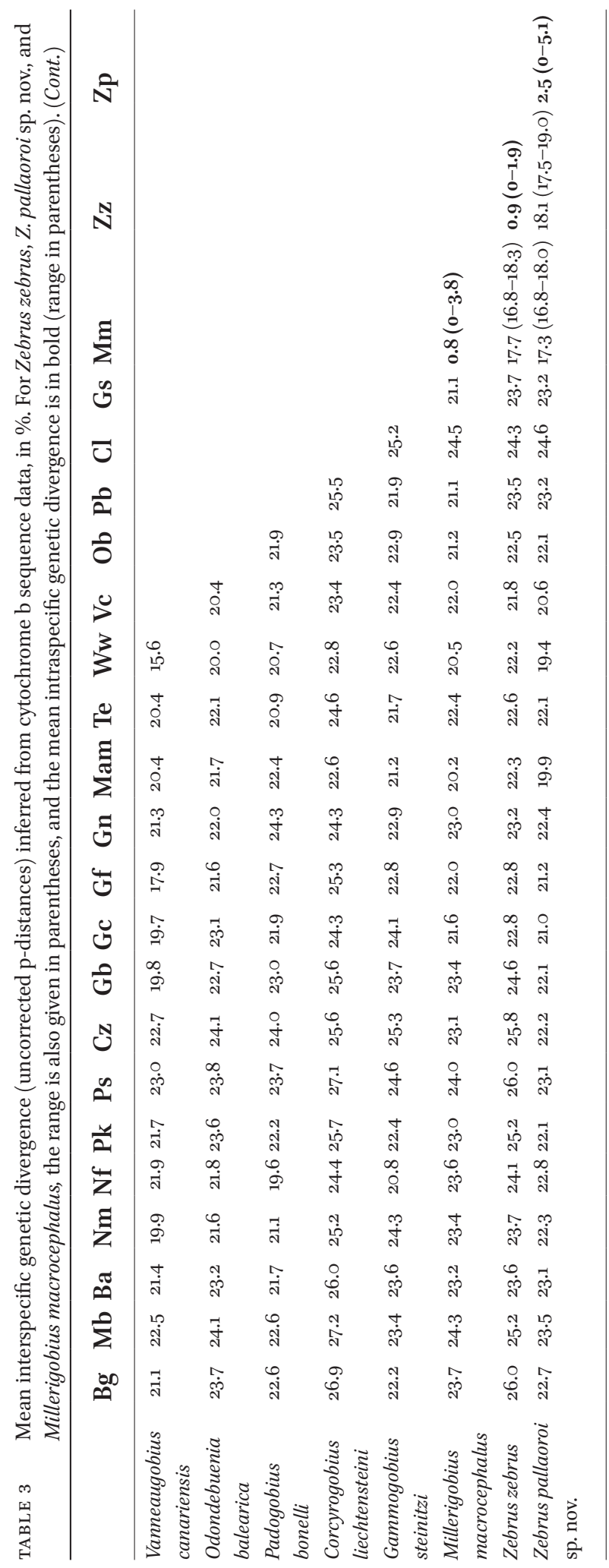




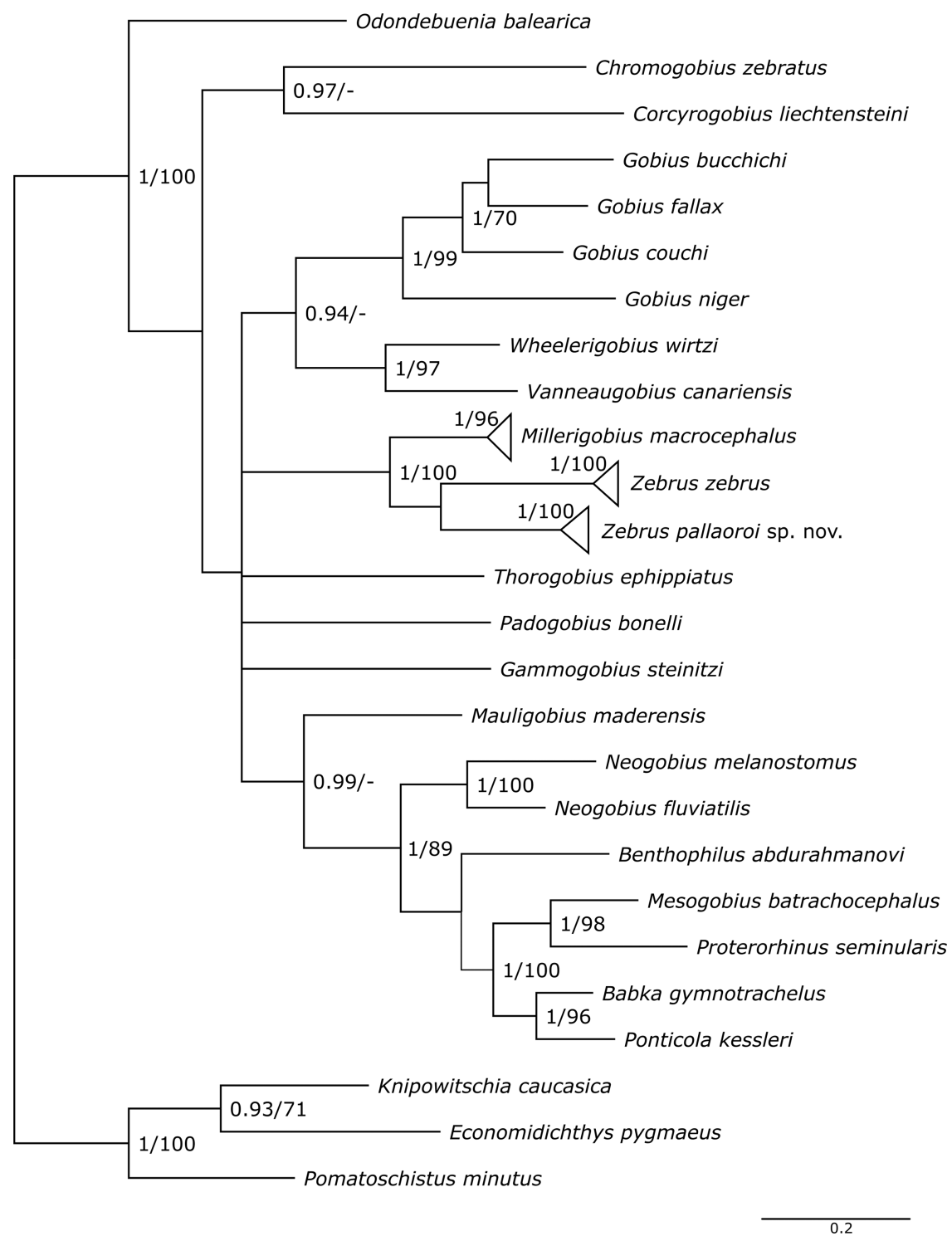

FIGURE 5 Bayesian 50\% majority-rule consensus tree estimation of phylogenetic relationships of analysed species from the Gobius-lineage sensu Agorreta et al. (2013) based on the mitochondrial gene cytochrome b. Numbers on branches are Bayesian posterior probabilities and maximum likelihood bootstrap values, respectively. Only values higher than 0.9 for posterior probability and $70 \%$ for bootstrap are shown.

was observed for rhodopsin. Thus, the three species within the clade are in polytomy according to both used markers (figs 5,6 , supplementary figs $\mathrm{S}_{1}, \mathrm{~S}_{2}$ ).

The mean p-distances on cytochrome $\mathrm{b}$ between the three species of the clade

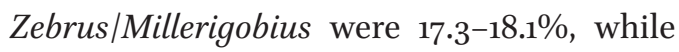
the mean distance between any of these three species and other species from the Gobius-lineage ranged between 19.4 and $26 \%$ (see table 3). Among the three species of the Zebrus/Millerigobius clade, the maximum 


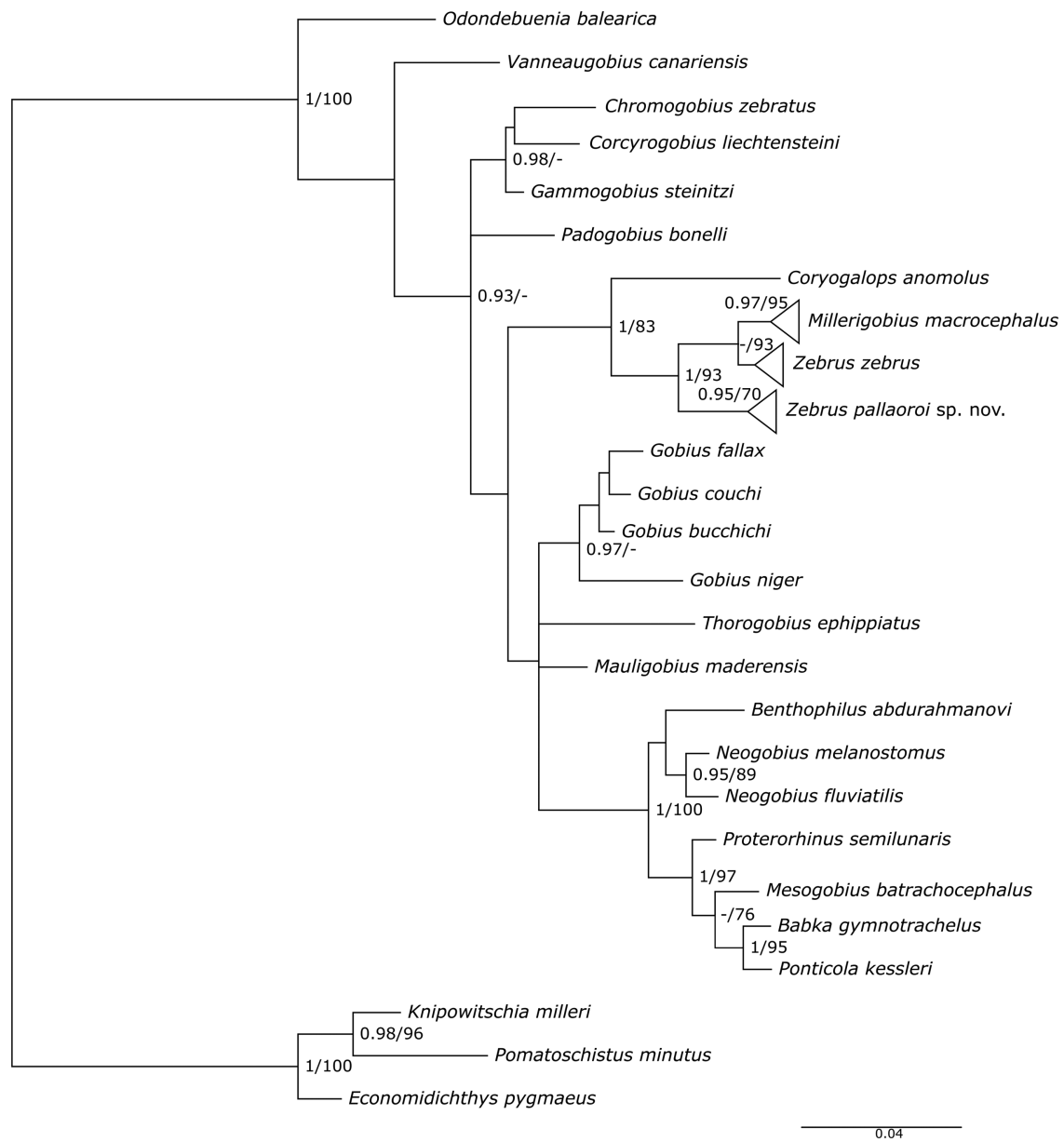

FIGURE 6 Bayesian 50\% majority-rule consensus tree estimation of phylogenetic relationships of analysed species from the Gobius-lineage sensu Agorreta et al. (2013) based on the nuclear gene rhodopsin. Numbers on branches are Bayesian posterior probabilities and maximum likelihood bootstrap values, respectively. Only values higher than 0.9 for posterior probability and $70 \%$ for bootstrap are shown.

intraspecific $\mathrm{p}$-distance was lowest in $Z$. zebrus $(1.9 \%)$ and the highest in Z. pallaoroi (5.1\%) (table 3). The mean p-distances between the three species on rhodopsin ranged between $0.97^{-1.31 \%}$ (see table 4). The distances on rhodopsin between the species of Zebrus and Millerigobius and other species of the Gobius-lineage were much higher and ranged between $4.6 \%$ and $7.9 \%$. The maximum intraspecific p-distances in the Zebrus/Millerigobius clade ranged between
$0.25 \%$ (in M. macrocephalus) and $0.62 \%$ (in Z. pallaoroi) on rhodopsin.

There was high haplotype diversity in cytochrome $\mathrm{b}$ for all three studied species within the Zebrus/Millerigobius clade (fig. 7), and no geographic structure was present in the haplotype networks. The only geographic structure was present in Z. pallaoroi, where haplotypes 63 and 64 (from the Aegean Sea) were very divergent from the remaining four haplotypes, which were from specimens 


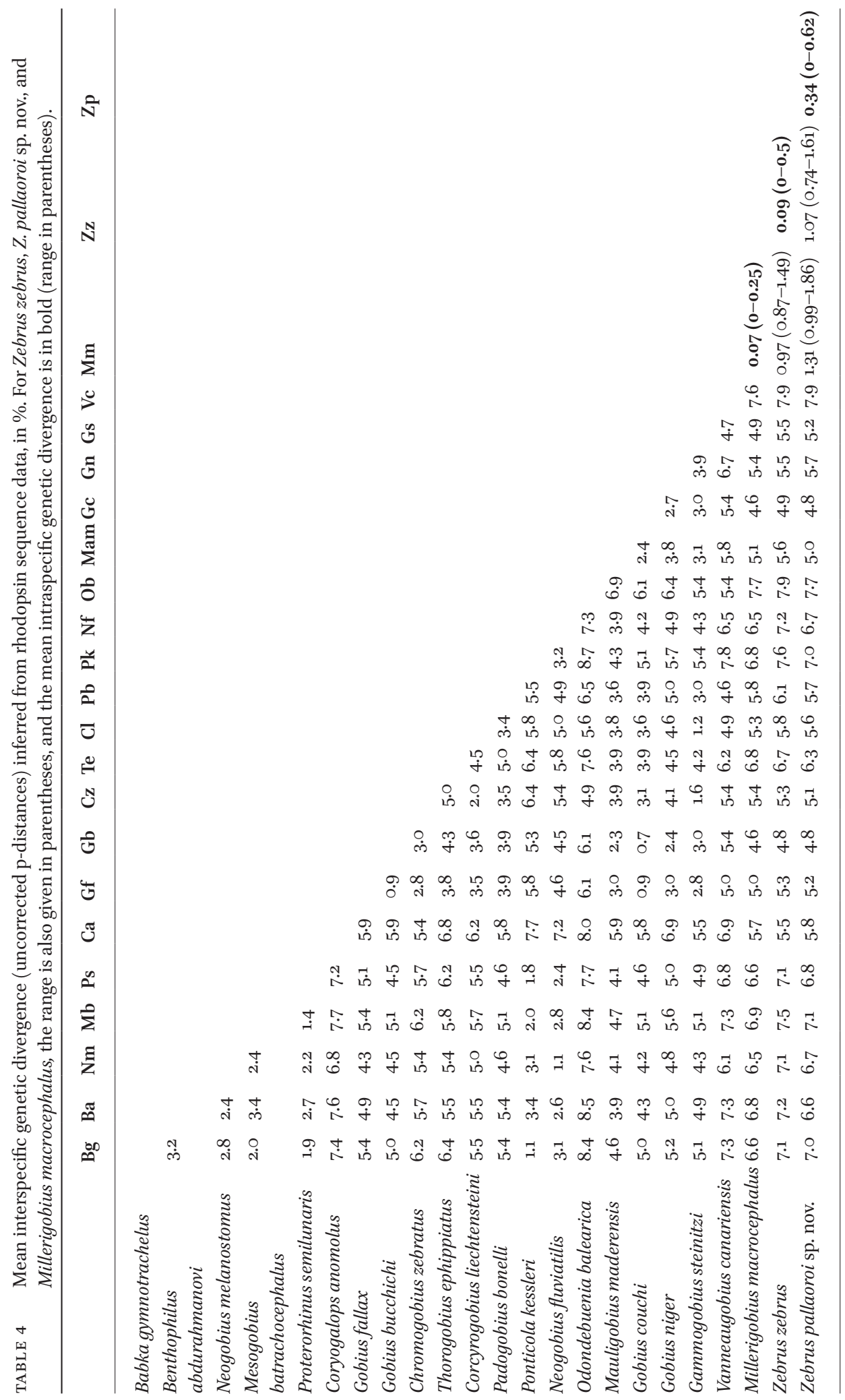




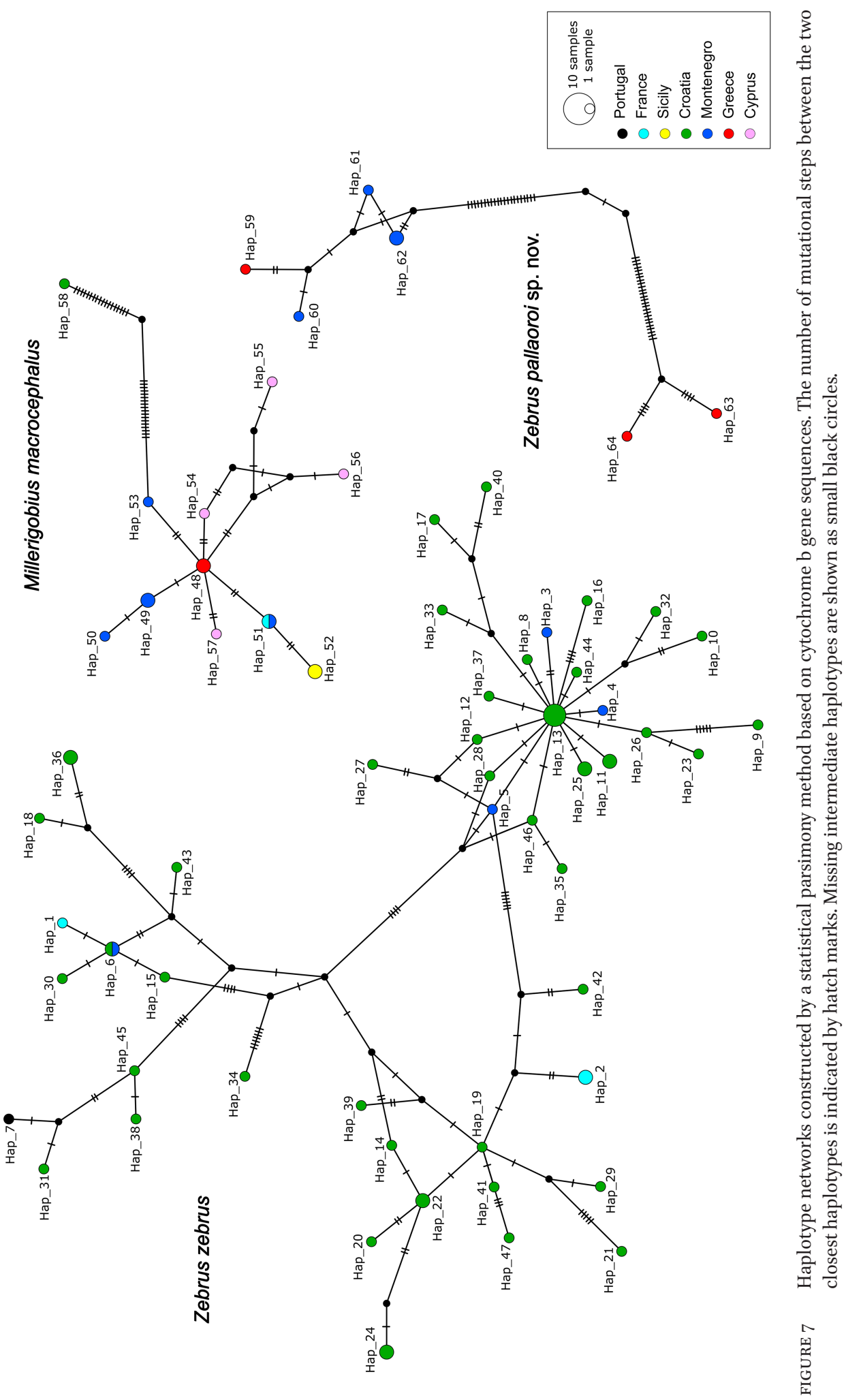


taken from the Adriatic and Ionian seas (at least 53 mutational steps), but there are too few samples to draw any conclusions. Also, haplotype 58 (the only sample from the northern Adriatic) of $M$. macrocephalus was very distant from the remaining haplotypes of this species (at least 37 mutational steps apart).

Rhodopsin haplotypes of each species from the Zebrus/Millerigobius clade grouped together in the haplotype network, and each group was separated by at least eight mutational steps from the other groups (i.e. from the other species) (fig. 8). The diversity of haplotypes was not high and there was no geographic structure in the haplotype network.

\section{Discussion}

For the majority of the gobiid genera included in the analyses, there is a lack of resolution in the phylogenetic tree nodes, congruently on both markers, placing most of the lineages to polytomy. This could indicate rapid evolution of Euro-Atlantic gobiids from the Gobiuslineage during a relatively short evolutionary time, which could coincide with the separation of the Mediterranean Sea from the Tethys or with some other important large-scale palaeogeographic event.

Molecular analyses of both employed markers placed Z. pallaoroi sp. nov. to the Zebrus/Millerigobius clade, and all three species were well-distinguished within the clade (figs 5, 6, supplementary figs S1, S2). All three species are reciprocally monophyletic on both studied markers. However, the relationships between the species were not resolved on either of the used markers (i.e., did not support a sister relationship of any pair of taxa within the clade), and the topology inside the clade resulting from two applied phylogenetic methods was not consistent. This is most likely a result of a speciation burst within the clade, i.e., a fast diversification of the three taxa within a short time. This, together with the comparable mutation rates of each studied molecular marker in the three species, led to a similar rate of accumulation of changes in the studied genes between all three species (tables 3,4 ) and resulted in the observed polytomy within the clade.

Despite the unresolved relationship of Zebrus/Millerigobius species from molecular analyses and apparent polytomy, the classification of the new species as a member of the genus Zebrus is strongly supported by morphological data, which simultaneously rejects its placement within the genus Millerigobius. There is a high morphological similarity between Z. zebrus and Z. pallaoroi sp. nov. on a generic level, and both species fit the genus redescription (see genus description above). Zebrus (data from present material; Miller, 1977, 1986) can be distinguished from Millerigobius (data from present material, Bath, 1973; Miller, 1977, 1986; Vanhove et al., 2011) by 1) interorbital 2.1-4.6 in eye diameter (vs. interorbital 1.2-1.9 in eye diameter in Millerigobius); 2) anterior nostril nasal tube with single process from the posterior rim (vs. anterior nostril nasal tube with no process from the rim in Millerigobius); 3) pectoral-fin rays 16-18 (vs. 1116 in Millerigobius); 4) pectoral fin with uppermost rays free from membrane (vs. uppermost rays enclosed in membrane except on tips in Millerigobius); 5) all three head canals present (vs. the posterior oculoscapular canal missing in Millerigobius); 6) row $b$ ends anteriorly below eye (vs. row $b$ ends anteriorly below posterior eye edge in Millerigobius ); 7) seven transverse suborbital rows of sensory papillae, four suborbital rows in front of row $b$, three above row $b$, two transverse suborbital rows below row $b$ (vs. seven transverse suborbital rows of sensory papillae, five suborbital rows in front 


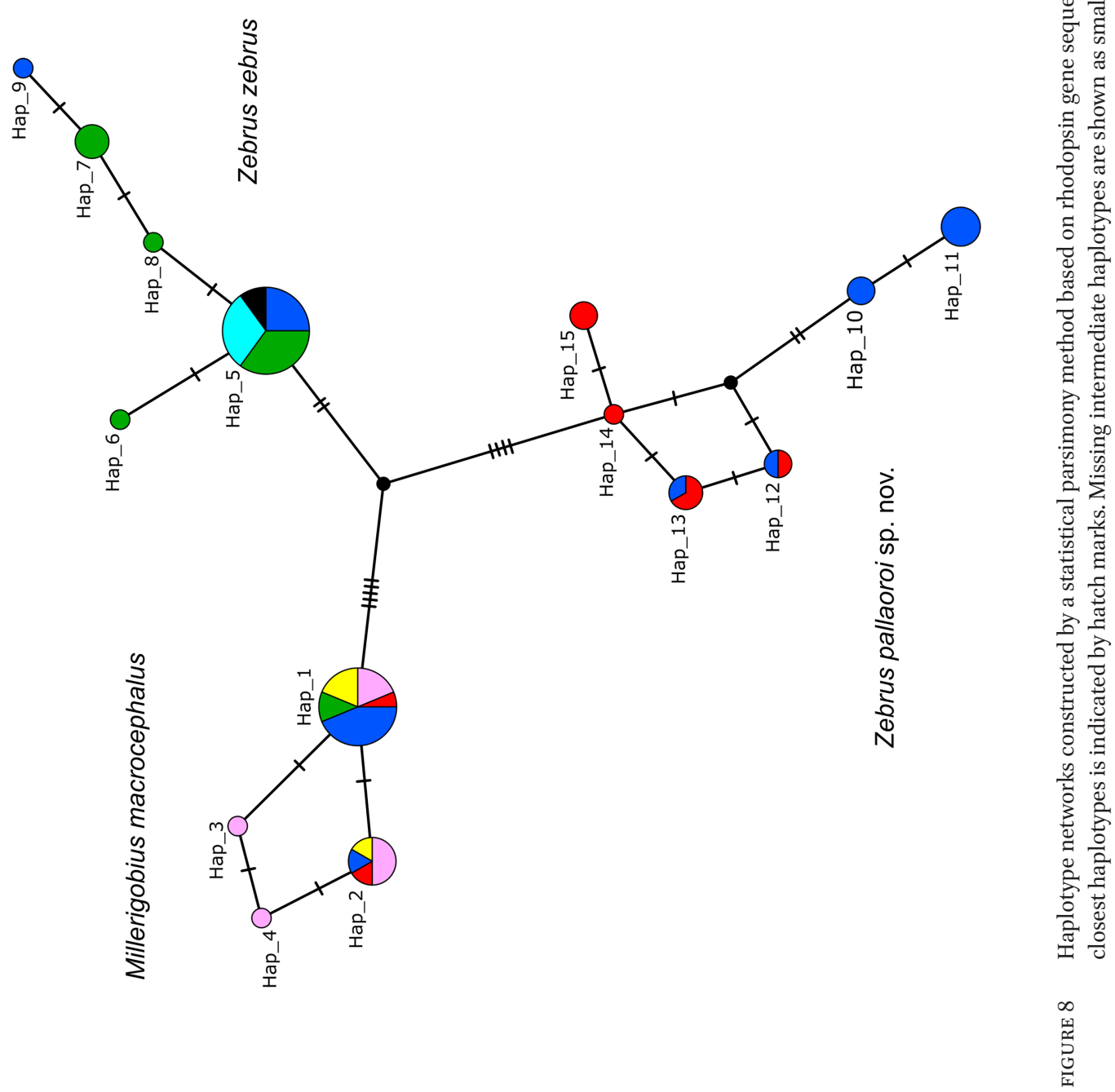


of row $b$, two above row $b$, single suborbital row below row $b$ in Millerigobius); 8) row $5 i$ opposite to row $6 i$ (vs. row $5 i$ above level of row $6 i$ or overlapping only with upper part of row $6 i$ in Millerigobius); 9) no interorbital papillae (vs. interorbital transversal row of papillae present in Millerigobius); 10) broad pale transverse stripe across anterior nape behind eyes, if present, doesn't include posterior part of eyes (vs. broad pale transverse stripe across anterior nape behind eyes, if present, includes posterior part of eyes in Millerigobius).

Molecular analyses have well-distinguished all three species within the clade, having all three reciprocally monophyletic on both studied markers. However, molecular analyses, having species relationships within the clade unresolved and with the topology from different applied phylogenetic methods inconsistent and in polytomy, were unable to suggest generic delimitation considering preservation of monophyly in the Zebrus/Millerigobius clade. Therefore, any taxonomical act above species level in the Zebrus/Millerigobius clade can be determined presently only from morphology. The two Zebrus species can be well-distinguished morphologically (see Remarks). However, morphological similarities between the two Zebrus species together with their shared differences vs. Millerigobius (see above in Discussion) do not justify erecting a third genus to accommodate the new species based solely on morphology. With no argument for genera delimitation based on molecular data or morphology, we have chosen the conservative approach of keeping the new species in the genus Zebrus until new data are gathered, such as the results of different genetic methods or the discovery of additional lineages belonging to the Zebrus/Millerigobius clade, that would suggest the opposite.

The divergence of the two Zebrus species is also clearly supported by genetic data. There is a very large difference on the mitochondrial marker cytochrome b (18\% p-distance, table 3). The interspecific differentiation on mitochondrial DNA is in general considerably high in the Gobius-lineage. Genetic distances observed between species of the genus Gobius ranged from 10 to $23 \%$ (Iglésias et al., 2016; Kovačić \& Šanda, 2016). The intergeneric genetic distances between genera of the Gobius-lineage observed in our study are in a similar range, being from 11 to $27.2 \%$ (table 3 ).

The differentiation between both Zebrus species on the nuclear marker rhodopsin is clear, although the genetic distance (only $1.1 \%$ ) is much smaller than on cytochrome b. This makes sense given that the level of polymorphism is lower in nuclear markers compared to mitochondrial ones, which have a higher mutation rate and associated quicker evolution (Wilson et al., 1985). Furthermore, even for rhodopsin, there was no haplotype sharing between the species, a phenomenon often observed in nuclear markers in related species, where even evolutionarily considerably divergent species could share the same haplotypes as a consequence of incomplete lineage sorting or sharing of ancestral polymorphisms (Marková et al., 2010). The intergeneric difference on rhodopsin in the Gobius-lineage is generally higher ( 1.1 to $8.5 \%$, mostly more than $3 \%$ ) than the interspecific ( 0.7 to $3 \%$ based on Zebrus and Gobius species included in our study) (table 4). Rhodopsin thus seems to be a suitable nuclear marker for distinguishing between genera in the Gobius-lineage. It also has a good potential to distinguish between species of the same genus, as demonstrated for Zebrus, where the mean and maximum values of intraspecific genetic distances were lower than interspecific (table 4).

There was a high haplotype diversity on cytochrome $b$ in all species of the 
clade Zebrus/Millerigobius. The maximum intraspecific distance was especially high in $Z$. pallaoroi sp. nov. (over $5 \%$ ), as well as $M$. macrocephalus (3.8\%), compared to Z. zebrus and European marine gobies from the Gobiuslineage, where values range between 1 and 2.2\% (Kovačić \& Šanda, 2016; Čekovská et al., 2020; Z. zebrus in this work). This high divergence of cytochrome b haplotypes in Z. pallaoroi sp. nov. could point to the existence of two evolutionary lineages within this species, but more material is needed to be able to draw any conclusions.

Zebrus pallaoroi $\mathrm{sp}$. nov. is a typical cryptobenthic species, all specimens were found between gravel and small boulders. In contrast to Z. zebrus, which is also a cryptobenthic fish usually reported from shallow waters (Nieto \& Alberto, 1992), but also found as deep as $36.4 \mathrm{~m}$ (Kesici \& Dalyan, 2019), $Z$. pallaoroi sp. nov. could be strictly specialized for very shallow infralittoral habitats, as all specimens were found near the shore at a maximum depth of $1 \mathrm{~m}$. It appears as though this is the third pair of similar species among Mediterranean cryptobenthic fishes occurring in two syntopic combinations, with the first combination comprising rocky and mixed habitats of an extended depth range in infralittoral zone shared by Z. zebrus, Chromogobius zebratus (Kolombatović, 1891), and Lepadogaster candolii Risso, 1810. The second comprises habitats of extremely shallow depths, and is shared by Z. pallaoroi, Chromogobius quadrivittatus (Steindachner, 1863), and Lepadogaster lepadogaster (Bonnaterre, 1788) (present results, Miller, 1986). It remains an outstanding question if speciation was a result of coevolution within a single guild of ancestors, or if the two similar syntopic groups were formed following speciation. However, knowledge of the new species is currently very limited, and further research will shed more light on the issue.

The distribution of small cryptobenthic gobies in the Mediterranean Sea is still not well characterized, and their known geographic ranges are continuously being extended with each new finding (e.g., Ordines et al., 2019).Zebrus pallaoroi sp. nov. could be a widespread species occurring in the northern part of the Mediterranean Sea. Yet, it is known only from the northern part of the southern Adriatic in Montenegro, the northern part of the Ionian Sea, and from two geographically distant localities on the Greek Aegean coast (fig. 4, supplementary table S1). It is possible that some previously published records of $Z$. zebrus from the northern (e.g., Kovačić, 2005; Kovačić \& Engin, 2009; Bogorodsky et al., 2010; Kovačić et al., 2012, 2013; Engin et al., 2018b; Kesici \& Dalyan, 2019) or western (reviewed in Kovačić et al., 2013) Mediterranean could in fact refer to Z. pallaoroi sp. nov, as both species of the genus could co-occur in the same area, as observed in the southern Adriatic. Unfortunately, the short morphological descriptions in the above-mentioned publications lack the presently established defining characters for species identification among the two Zebrus species. A similar problem occurred with the $G$. incognitus description, which called into question all historical distribution records of $G$. bucchichi (Kovačić \& Šanda, 2016).

Apart from the new species description, material in this study provides additional data on the distribution of species within the Zebrus/Millerigobius clade. The Z. zebrus specimen from Faro, Portugal (table S1), represents the westernmost record of this species (fig. 4), which occurs in the Mediterranean and Black seas (see the map of reviewed records in Kovačić et al., 2013), and was so far reported also 
from the Atlantic coast of southern Spain up to Huelva (Nieto \& Alberto, 1992). All records by Nieto and Alberto (1992) were from tidal pools, whereas the specimen from Faro was collected during a dive over rocky habitat in an otherwise sandy bottom area, several $\mathrm{km}$ offshore at a depth of $14 \mathrm{~m}$. Millerigobius macrocephalus is reported for the first time from Cyprus in this work (fig. 4, supplementary table S1). This represents the fourth record of this species from the Levant Sea, with earlier records known from Israel and Lebanon (Miller, 1977).

\section{Acknowledgements}

This project was financially supported by the Grant Agency of Charles University (GAUK) no 1192217. RŠ received support by the Ministry of Culture of the Czech Republic (DKRVO 2019-2023/6.III.c National Museum, ooo23272). MK was supported in part by a grant from the Croatian Science Foundation under the project IP-2016-06-9884 and in part by a grant from the Croatian Science Foundation under the project IP-2016-06-5251. We are pleased to thank Dr. Ulrich Schliewen, Department of Ichthyology, Bavarian Natural History Collections, SNSB Bavarian State Collection of Zoology (ZSM) for preparing the X-ray. We are grateful to Stamatis Zogaris (HCMR, Athens), Konstantinos Moustakas, and Ioulianos Pantelides (DFMR, Cyprus), and Venera Ferrito (University of Catania) for their help in obtaining additional specimens used for genetic data and comparative material. The collection of a part of the comparative material was supported by the EU $\mathrm{FP}_{7}$ project ASSEMBLE at CCMar/Centre of Marine Sciences of Algarve, Faro, Portugal, and Observatoire oceanologique de Banyuls/ Mer, Laboratoire Arago, Banyuls/Mer. We are gratetul to three anonymous reviewers for constructive comments. Lastly, we also thank Tyler J. Kohler for proofreading.

\section{Comparative material examined}

Millerigobius macrocephalus:NMP P6V142686, juvenile of unidentified sex, $14.28+3.97 \mathrm{~mm}$, Îll Gross, Banyuls sur Mer, France; NMP P6V 145158, male, $25.7+6.25 \mathrm{~mm}$, Aci Trezza, Sicily, Italy; NMP P6V 14416, male, $23.73+6.01 \mathrm{~mm}$, NMP P6V 14417, female, $22.24+5.66 \mathrm{~mm}$, NMP P6V 14418, female, $31.31+5.35 \mathrm{~mm}$, all three Strp, Boka Kotorska, Adriatic Sea.

\section{Supplementary material}

Supplementary material is available online at: https://doi.org/10.6084/mg.figshare.13656707

\section{References}

Agorreta, A., San Mauro, D., Schliewen, U., Van Tassell, J.L., Kovačić, M., Zardoya, R. \& Rüber, L. (2013) Molecular phylogenetics of Gobioidei and phylogenetic placement of European gobies. Mol. Phylogenet. Evol., 69, 619-633.

Akihito, Iwata, A., Kobayashi, T., Ikeo, K., Imanishi, T., Ono, H., Umehara, Y., Hamamatsu, C., Sugiyama, K., Ikeda, Y., Sakamoto, K., Fumihito, A., Ohno, S. \& Gojobori, T. (2000) Evolutionary aspects of gobioid fishes based upon a phylogenetic analysis of mitochondrial cytochrome b genes. Gene, 259, 5-15.

Bath, H. (1973) Wiederbeschreibung der Grundelart Gobius macrocephalus Kolombatovic aus dem Mittelmeer und Aufstellung einer neuen Gattung Millerigobius (Teleostei: Gobioidea: Gobiinae). Senckenb. Biol., 54, 303-310.

Birdsong, R.S., Murdy, E.O. \& Pezold, F.L. (1988) A study of the vertebral column and median fish 
osteology in gobioid fishes with comments on gobioid relationships. Bull. Mar. Sci., 42, 174-214. Bogorodsky, S., Kovačić, M., Ozen, O. \& Bilecenoglu, M. (2010) Records of two uncommon goby species (Millerigobius macrocephalus, Zebrus zebrus) from the Aegean Sea. Acta Adriat., 51, 217-222.

Boissin, E., Hoareau, T.B. \& Berrebi, P. (2011) Effects of current and historic habitat fragmentation on the genetic structure of the sand goby Pomatoschistus minutus (Osteichthys, Gobiidae). Biol. J. Linn. Soc. Lond., 102, 175-198.

Brown, J.E. \& Stepien, C.A. (2008) Ancient divisions, recent expansions: Phylogeography and population genetics of the round goby Apollonia melanostoma. Mol. Ecol., 17, 2598-2615.

Čekovská, K., Šanda R., Eliášová, K., Kovačić, M., Zogaris, S., Pappalardo, A.M., Soukupová, T. \& Vukić, J. (2020) Population genetic diversity of two marine gobies (Gobiiformes: Gobiidae) from the North-Eastern Atlantic and the Mediterranean Sea. J. Mar. Sci. Eng., 8, 792.

Clement, M., Posada, D. \& Crandall, K.A. (2000) TCS: a computer program to estimate gene genealogies. Mol. Ecol., 9, 1657-1659.

de Buen, F. (1930) Sur une collection de Gobiinae provenant du Maroc. Essai de synopsis des espèces de l'Europe. Bull. Soc. Sci. Nat. Maroc, 10, $120-147$.

Engin, S. \& İnnal, D. (2017) A new species of Pomatoschistus (Teleostei: Gobiidae) from Southern Anatolia. Zool. Middle East, 63, 316-324.

Engin, S., Irmak, E., Seyhan, D., Akdemir T. \& Kesin, A.C. $(2018 \mathrm{~b})$ Gobiid fishes of the coastal zone of the Northeastern Aegean Sea. Mar. Biodivers., 48, 1073-1084.

Engin, S., Larson, H. \& Irmak, E. (2018a) Hazeus ingressus sp. nov. a new goby species (Perciformes: Gobiidae) and a new invasion in the Mediterranean Sea. Mediterr. Mar. Sci., 19, 316-325.
Engin, S. \& Seyhan, D. (2017) A new species of Pomatoschistus (Teleostei, Gobiidae): the Mediterranean's smallest marine fish. J. Fish Biol., 91, 1208-1223.

Fricke, R., Eschmeyer, W.N. \& Fong, J.D. (2020a) Eschmeyer's catalog of fishes: Species by family/ subfamily. (http://researcharchive.calacademy. org/research/ichthyology/catalog/SpeciesBy Family.asp). Electronic version accessed 20 October 2020.

Fricke, R., Eschmeyer, W.N. \& Van der Laan, R. (eds) (2020b) Eschmeyer's catalog of fishes: Genera, species, references. (http://researcharchive. calacademy.org/research/ichthyology/catalog/ fishcatmain.asp). Electronic version accessed 20 October 2020.

Gysels, E.S., Hellemans, B., Patarnello, T. \& Volckaert, F.A.M. (2004) Current and historic gene flow of the sand goby Pomatoschistus minutus on the European Continental Shelf and in the Mediterranean Sea. Biol.J. Linn. Soc. Lond., 83, 561-576.

Hall, T.A. (1999) BioEdit: a user-friendly biological sequence alignment editor and analysis program for Windows 95/98/NT. Nucleic Acids Symp. Ser., 41, 95-98.

Hebert, P.D.N., Cywinska, A., Ball, S.L. \& deWaard, J.R. (2003) Biological identifications through DNA barcodes. Proc. R. Soc. Lond. B., 270, 313-321. Iglésias, S.P., Frotté, L. \& Sellos, D.Y. (2016) Gobius salamansa, a new species of goby (Gobiidae) from the Cape Verde Islands supported by a unique cephalic lateral line system and DNA barcoding. Ichthyol. Res., 63, 356-369.

Kesici, N.B. \& Dalyan, C. (2019) New record of the zebra goby, Zebrus zebrus (Risso, 1827), in the Bosphorus strait (Turkey). Turkish J. Biosci. Collect., 3, 8-10.

Kovačić, M. (2005) An annotated checklist of the family Gobiidae in the Adriatic Sea. Ann. Ser. Hist. Nat., 15, 21-44.

Kovačić, M., Bogorodsky S.V. \& Mal A.O. (2019a) Two new species of Hetereleotris (Perciformes: 
Gobiidae) from the Red Sea. Zootaxa, 4608, 501-516.

Kovačić, M., Bonello, J.J. \& Evans, J. (2013) Three new records of Gobiidae from Malta with morphology, colouration and identification of the smallest known juveniles of two small gobiid species. Cybium, 37, 233-239.

Kovačić, M. \& Engín, S. (2009) First record of the zebra goby, Zebrus zebrus (Gobiidae), in the Black sea. Cybium, 33, 83-84.

Kovačić, M., Ordines F., Ramirez-Amaro S. \& Schliewen, U.K. (2019b) Gymnesigobius medits (Teleostei: Gobiidae), a new gobiid genus and species from the western Mediterranean slope bottoms. Zootaxa, 4651, 513-530.

Kovačić, M., Ordines, F. \& Schliewen, U.K. (2016) A new species of Speleogobius (Teleostei: Gobiidae) from the Western Mediterraenean Sea. Zootaxa, 4066, 301-310.

Kovačić, M., Ordines, F. \& Schliewen, U.K. (2017) A new species of Buenia (Teleostei: Gobiidae) from the western Mediterranean Sea, with the description of this genus. Zootaxa, 4250, 447-46o.

Kovačić, M., Ordines, F. \& Schliewen, U.K. (2018) A new species of Buenia (Perciformes: Gobiidae) from the Western Mediterranean slope bottoms, the redescription of Buenia jeffreysi and the first Balearic record of Buenia affinis. Zootaxa, 4392, 267-288.

Kovačić, M. \& Šanda, R. (2016) A new species of Gobius (Perciformes: Gobiidae) from the Mediterranean Sea and the redescription of Gobius bucchichi.J. Fish Biol., 88, 1104-1124.

Kovačić, M., Šanda, R., Kirinčić, M. \& Zanella, D. (2012) Geographic distribution of gobies (Gobiidae) in the Adriatic Sea with thirteen new records for its southern part. Cybium, 36 , 435-445.

Lanfear, R., Frandsen, P.B., Wright, A.M., Senfeld, T. \& Calcott, B. (2017) PartitionFinder 2: New methods for selecting partitioned models of evolution for molecular and morphological phylogenetic analyses. Mol. Biol. Evol., 34, $77^{-}-773$.

Larmuseau, M.H.D., Huyse, T., Vancampenhout, K., Van Houdt, J.K.J. \& Volckaert, F.A.M. (2010) High molecular diversity in the rhodopsin gene in closely related goby fishes: A role for visual pigments in adaptive speciation? Mol. Phylogenet. Evol., 55, 689-698.

Leigh J.W. \& Bryant, D. (2015) POPART: full-feature software for haplotype network construction. Methods Ecol. Evol., 6, 1110-1116.

Machordom, A. \& Doadrio, I. (2001) Evidence of a cenozoic Betic-Kabilian connection based on freshwater fish phylogeography (Luciobarbus, Cyprinidae). Mol. Phylogenet. Evol., 18, 252-263. Marková, S., Šanda, R., Crivelli, A., Shumka, S., Wilson, I.F., Vukić, J., Berrebi, P. \& Kotlík, P. (2010) Nuclear and mitochondrial DNA sequence data reveal the evolutionary history of Barbus (Cyprinidae) in the ancient lake systems of the Balkans. Mol. Phylogenet. Evol., 55, 488-500.

Miller, P.J. (1966) A new genus and species of gobiid fish from the eastern Mediterranean. Ann. Mag. Nat. Hist., Ser. 13, 8, 161-172.

Miller, P.J. (1973) Gobiidae. In: J.-C. Hureau \& T. Monod (Eds) Check-list of the Fishes of the Northeastern Atlantic and of the Mediterranean, pp. 483-518. Unesco, Paris.

Miller, P.J. (1977) Gobies from Rhodes and systematic features of Zebrus zebrus (Teleostei: Gobiidae). Zool. J. Linn. Soc., 6o, 339-362.

Miller, P.J. (1986) Gobiidae. In: P.J.P. Whitehead, M.L. Bauchot, J.C. Hureau, J. Nielsen \& E. Tortonese (Eds) Fishes of the North-eastern Atlantic and the Mediterranean 3, pp. 1019-1085. UNESCO, Paris.

Miller, P.J. \& El-Tawil,M.Y. (1974) A multidisciplinary approach to a new species of Gobius (Teleostei: Gobiidae) from southern Cornwall. J. Zool., 174, 539-574. 
Miller, M.A., Schwartz, T., Pickett, B.E., He, S., Klem, E.B., Scheuermann, R.H., Passarotti, M., Kaufman, S. \& O'Leary, M.A. (2015). A RESTful API for Access to Phylogenetic Tools via the CIPRES Science Gateway. Evol. Bioinform., 11, 43-48.

Neilson, M.E. \& Stepien, C.A. (20o9a) Escape from the Ponto-Caspian: Evolution and biogeography of an endemic goby species flock (Benthophilinae: Gobiidae: Teleostei). Mol. Phylogenet. Evol., 52, 84-102.

Neilson, M.E. \& Stepien, C.A. (2009b) Evolution and phylogeography of the tubenose goby genus Proterorhinus (Gobiidae: Teleostei): evidence for new cryptic species. Biol. J. Linn. Soc. Lond., 96, 664-684.

Nieto, P. \& Alberto, L.J. (1992) The presence of Zebrus zebrus (Risso, 1826) (Gobiidae) on the Atlantic coast of Spain. Cybium, 16, 137-144.

Ordines, F., Kovačić, M., Vivas, M., García-Ruiz, C. \& Guijarro, B. (2019) Westernmost Mediterranean records of three gobiid species (Actinopterygii: Perciformes: Gobiidae). Acta Ichthyol. Piscat., 49, $275^{-282}$.

Ronquist, F., Teslenko, M., van der Mark, P., Ayres, D.L., Darling, A., Höhna, S., Larget, B., Liu, L., Suchard, M.A. \& Huelsenbeck, J.P. (2012) MrBayes 3.2: efficient Bayesian phylogenetic inference and model choice across a large model space. Syst. Biol., 61, 539-542.

Šanda, R. \& Kovačić, M. (2009) First record of Gobius couchi (Gobiidae) in the Ionian Sea. Cybium, 33, 249-250.

Šanda, R., Vukić, J., Choleva, L., Kř́žžek, J., Šedivá, A., Shumka, S. \& Wilson, I.F. (2008) Distribution of loach fishes (Cobitidae, Nemacheilidae) in Albania, with genetic analysis of populations of Cobitis ohridana. Folia Zool., 57, 42-5o.

Sanzo, L. (1911) Distribuzione delle papille cutanee (organi ciatiforme) e suo valore sistematico nei Gobi. Mitt. Zool. Stat. Neap., 20, 249-328.

Saruwatari, T., Andres Lopez, J. \& Pietsch, T.W. (1997) Cyanine blue: a versatile and harmless stain for specimen observation. Copeia, 1997, 840-841.

Schliewen, U.K. \& Kovačić, M. (2008) Didogobius amicuscaridis spec. nov. and D. wirtzi spec. nov., two new species of symbiotic gobiid fish from São Tomé and Cape Verde islands. Spixiana, 31, 247-261.

Schliewen, U.K., Kovačić, M., Cerwenka, A.F., Svensen, R. \& Ordines, F. (2019) Lebetus patzneri (Teleostei: Gobiidae), a new goby species from the Balearic Islands, western Mediterranean, with first records of Lebetus guilleti (Le Danois, 1913) from this area and Norway, and with notes on its biology. Zootaxa, 4706, 231-254.

Schliewen, U.K., Wirtz, P. \& Kovačić, M. (2018) Didogobius janetarum sp. nov., a new cryptobenthic goby species from the Cape Verde Islands (Teleostei: Gobiidae). Zootaxa, 4438, 381-393.

Stamatakis, A. (2014) RAxML version 8: a tool for phylogenetic analysis and post-analysis of large phylogenies. Bioinformatics, 30, 1312-1313.

Stefanni, S., Gysels, E.S., Volckaert, F.A.M. \& Miller, P.J. (2003) Allozyme variation and genetic divergence in the sand goby, Pomatoschistus minutus (Teleostei: Gobiidae). J. Mar. Biolog. Assoc. U.K., 83, 1143-1149.

Stefanni, S. \& Thorley, J.L. (2003) Mitochondrial DNA phylogeography reveals the existence of an evolutionarily significant unit of the sand goby Pomatoschistus minutus in the Adriatic (Eastern Mediterranean). Mol. Phylogenet. Evol., 28, 6o1-6o9.

Stephens, M., Smith, N.J. \& Donnelly, P. (2001) A new statistical method for haplotype reconstruction from population data. Am. J. Hum. Genet., 68, 978-989.

Tamura, K., Stecher, G., Peterson, D., Filipski, A. \& Kumar, S. (2013) MEGA6: molecular evolutionary genetics analysis version 6.o. Mol. Biol. Evol., 30, 2725-2729.

Taylor, M.S. \& Hellberg, M.E. (2005) Marine radiations at small geographic scales: speciation 
in Neotropical reef gobies (Elacatinus). Villesen, P. (2007) FaBox: an online toolbox for Evolution, 59, 374-385. fasta sequences. Mol. Ecol. Notes, 7, 965-968.

Thacker, C.E. \& Roje, D.M. (2011) Phylogeny of Vukić, J., Kovačić, M., Zogaris, S. \& Šanda, R. (2016) Gobiidae and identification of gobiid lineages. System. Biodivers., 9, 329-347.

Vanhove, M.P.M., Kovačić, M., Koutsikos, N.E., Zogaris, S., Vardakas, L.E., Huyse, T. \& Economou, A.N. (2011) First record of a landlocked population of marine Millerigobius macrocephalus (Perciformes: Gobiidae): Observations from a unique spring-fed karstic lake (Lake Vouliagmeni, Greece) and phylogenetic positioning. Zool. Anz., 250, 195-204.

Victor, B. (2014) Three new endemic cryptic species revealed by DNA barcoding of the gobies of the Cayman Islands (Teleostei: Gobiidae).J. Ocean. Sci. Found., 12, 25-6o. Rediscovery of Knipowitschia goerneri and its molecular relationships with other European northern Mediterranean Knipowitschia species (Teleostei: Gobiidae). Ichthyol. Explor. Freshw., 26, 363-372.

Wilson, A.C., Cann, R.L., Carr, S.M., George, M., Gyllenstenis, U.B., Helm-Bychowski, K.M., Higuchi, R.G., Palumbi, S.R., Prager, E.M., Sage, R.D. \& Stoneking, M. (1985) Mitochondrial DNA and two perspectives on evolutionary genetics. Biol. J. Linn. Soc. Lond., 26, 375-40o.

RECEIVED: 10 JULY 2020 | REVISED AND

ACCEPTED: 29 JANUARY 2021

EDITOR: IVANA BUJ 